\title{
Directed Technological Change in a post-Keynesian Ecological Macromodel ${ }^{\text {th }}$
}

\author{
Asjad Naqvi ${ }^{\mathrm{a}, \mathrm{b}, *}$, Engelbert Stockhammer ${ }^{\mathrm{c}}$ \\ ${ }^{a}$ Institute for Ecological Economics, Vienna University of Economics and Business, Austria. \\ ${ }^{b}$ International Institute for Applied Systems Analysis, Austria. \\ ${ }^{c}$ School of Economics, Faculty of Arts and Social Sciences, Kingston University, UK
}

\begin{abstract}
This paper presents a post-Keynesian ecological macro model, which is stock-flow consistent, and incorporates directed technological change using the induced innovation hypothesis. Private and public R\&D spending across three competing, yet complementary inputs - Labor, Capital, and Resources - follow a portfolio allocation decision, where inputs with relatively higher growth in costs see higher R\&D investments and productivity gains. Two policy experiment are reported; a market-based Resource tax increase, and a more centralized green policy where public R\&D budget is shifted towards Resource-saving technologies. We highlight that in the presence of labor market institutions, which give rise to hysteresis, and limited R\&D budgets, a policy of continuous Resource tax growth is needed to direct technological change to achieve a greener economy. This needs to be coupled with planned government spending adjustment to spur demand and boost investment. The findings also suggest that a mix of market-based and centralized policies may be optimal.
\end{abstract}

Keywords: directed technological change, research and development, post-Keynesian economics, stock-flow consistency, climate policies

\footnotetext{
"We would like to thank the editor and two anonymous referees for their valuable comments. We gratefully acknowledge support from the Austrian Central Bank (Oesterreichische Nationalbanks (OeNB)) Anniversary Fund Grant number 17400. All errors are our own.

*Corresponding author: snaqvi@wu.ac.at
} 


\section{Introduction}

In 2009, OECD countries signed the Green Growth Deceleration in a bid to achieve higher growth while simultaneously tackling aspects of resource use and emissions (OECD 2011). Following the 2015 Paris Accord, the European Union (EU) has set itself an ambitious target of reducing emissions by at least $40 \%$ by 2030 relative to 1990 levels (EC 2016a). Both agreements signal a shift in the policies of high-income countries that want to achieve "sustainable growth" through "green" investment and innovation (OECD 2015; EIB 2015). In the EU, "green growth" forms an integral part of the holistic EU2020 strategy, which aims to tackle issues of environment, unemployment, and inequality (EC 2010). A recurring theme across these agreements is a focus on research and development $(\mathrm{R} \& \mathrm{D})$ which can simultaneously enable green innovation, productivity gains, and job creation. This is also reflected in the reclassification of the R\&D from an expenditure category to an investment category in the European System of Accounts (ESA) in 2010 in order to better highlight its contribution towards overall economic growth (EC 2017). Additionally, the EU also proposes to increase R\&D spending to at least $3 \%$ of GDP by 2020 , up from the current $2 \%$ to bring it in line with other high income regions (EC 2016b).

While there is consensus among economists that higher R\&D spending is positively correlated with higher levels of innovation, productivity gains, and growth, the channels through which this materializes has been a subject of decades of research (Dosi 1988; Rousseau 2008; Pollitt et al. 2010; Marangoni and Tavoni 2014). In neo-classical models, technological change is usually defined as efficiency gains in inputs resulting from improved productivity. ${ }^{1}$ While in standard Solow-type growth models, productivity gains are introduced exogenously, usually on the whole production function (Solow 1956), endogenous growth models discuss how input-specific technological change can be determined within the model. One key assumption used to explain endogenous technological change is the induced innovation hypothesis (Hicks 1932) which states that inputs with rising prices will spur higher investments in those inputs to reduce costs in order to maximize profits (Romer 1990; Tavani and Zamparelli 2017). Thus by manipulating price signals, whether through taxes or subsidies or increasing R\&D, or a combination of these, a policy planner can "direct" technological change towards a certain input. This logic has also been applied to climate change models where the discussion focuses transitions to a low emissions economy by shifting resources away from "brown" sectors towards "green" sectors and is also supported by a growing body of empirical literature (Löschel 2002; Popp et al. 2010).

Unlike standard exogenous growth models, endogenous technological change models acknowledge the role of path dependencies, role of input substitutability, and the role of policy interventions in markets under certain conditions (Acemoglu et al. 2012, 2016; Aghion et al. 2016). Despite these advantages,

\footnotetext{
${ }^{1}$ This is distinctly different from a Schumpeterian technological change, which results in the probabilistic creation of new technologies through invention, innovation, and diffusion (Schumpeter 1934; Nelson and Winter 1977).
} 
endogenous technological change models have three shortcomings. First, they operate in a world with perfect foresight, for example without unemployment, thus miss out on crucial aspects of environmental policies that potentially might result in negative effects on the economy (Daly 1991). For example in the EU, secular stagnation, unemployment, and inequality remain a persistent problem since the 2008 financial crisis (EC 2016c). Second, European Union (EU) countries have strong labor laws and wage bargaining institutions that have a strong impact on wage formation. This indirectly encourages $R \& D$ investment in labor-saving technologies as opposed to resource-saving technologies. Third, the role of limited finance is not discussed. Post-2008 financial crisis, investment levels on the whole have gone down, while firms are unwilling to invest in high-risk "green" projects (EC 2016c). This implies that the conditions for green investment needs to be created through regulation or state-led investment schemes where the state itself might need to fill in the role of the innovator (Mazzucato 2015, 2016).

With rising skepticism of supply-side market-based solutions provided by mainstream climate models (Spash 2012; Stern 2016; Pindyck 2017), non-mainstream models, mostly stemming from the post-Keynesian school, have recently emerged (Hardt and O'Neill 2017). These models do away with perfect foresight assumptions and introduce adaptive behavior in a world with uncertainty. They also discuss at length, the role of institutions and regulations. Like endogenous growth theory models, they also ascribe to pathdependencies, but go a step further to also include endogenous institutional change. However, since nonmainstream demand-driven climate models are relatively new, they lack a proper treatment of supplyside environmental constraints (Fontana and Sawyer 2013; Rezai et al. 2013) and a detailed exposition of endogenous technological change.

In this paper we provide a conceptual modeling framework that integrates the demand-driven postKeynesian theory with the induced innovation hypothesis. We develop a model, where demand for capital and consumption goods is met by the firms that require three inputs - Labor, Capital, and Resources - to produce outputs. Resource represents the general material intensity of the economy where less is preferred to more. Private firms produce $R \& D$ as part of general investment in the economy. The R\&D budget is determined through firm's profitability and government sector's revenue both of which are assumed procyclical. We propose a novel way of modeling R\&D decisions, where, in a limited finance environment, the R\&D allocation across the three inputs follow a portfolio choice-like decision. Following the induced innovation hypothesis, we assume that the inputs with the highest growth in costs sees the highest increase in the R\&D investment share over time. This determines the level of productivity gains across all inputs. The model allows for involuntary unemployment, and wage dynamics depend on target wages shaped by labor market institutions and path-dependent social norms. This can result in constellations where workers try to index wage growth to labor productivity growth, which in turn induces firms to direct innovation towards labor-saving technological change.

We report two policy experiments. In the first experiment, the impacts of a market-based one-off versus 
continuous resource (or carbon) tax increase are compared. In the second experiment, we combine the continuous resource tax increase with an autonomous increase in public $R \& D$ (or green $R \& D$ ) expenditure on Resources and discuss the effects of hybrid policies. Model results show that in a world of demand-led growth, endogenous technological change with complementary inputs, strong labor institutions and limited finance, market-based climate policy instruments need to be continuously increased over a long-time horizon rather than pursuing a one-off optimal target level of, say, environmental taxes or subsidies in order to achieve a green transition. Thus one does not need to stop economic growth (Acemoglu et al. 2012) or solely rely on command-and-control policies (Lamperti et al. 2016) to achieve a green transition under the input-complementarity assumption. This, however, needs to be combined with carefully managed public spending to ensure demand generation to keep the economy on a growth path. Results also show that a mix of market-based policies (e.g. carbon taxes) combined with centralized command-and-control policies (e.g. green public R\&D) might be optimal to achieve a greener economy.

The remaining paper is structured as follows. Section 2 reviews the literature in detail. Section 3 presents the model, and Section 4 presents the simulation results. Section 5 provides conclusions and discusses potential extensions.

\section{Literature}

This section discusses various schools of thought, their treatment of climate change, and in particular their discussion of technological change. The first subsection reviews the developments in neo-classical endogenous growth theory and its contribution to climate models. The second subsection explores nonmainstream schools, their applications to climate change, and their treatment of technological change.

\subsection{Neo-classical environmental economics}

Technological change in neo-classical models is introduced as either exogenous or endogenous (Löschel 2002; Jaffe et al. 2003; Rousseau 2008; Popp et al. 2010). Exogenous technological change models are derived from the Solow framework (Solow 1956), where an exogenous productivity shock to the overall production function, or specific inputs (for example, labor augmenting technological change), causes the production possibilities frontier to shift outwards, resulting in higher growth. In climate economics, the Solow framework was first adapted by Nordhaus in the widely-cited DICE framework (Nordhaus 1994; Nordhaus and Sztorc 2013), which now forms the backbone of the Integrated Assessment Models (IAMs). In their simplest form, IAMs assume that economic activity results in emissions, that causes temperature and radiative forces to increase, negatively feeding back on the economy though an environmental damage function. The solution to this problem is the price of carbon, which is derived as the equilibrium condition between marginal damage and marginal abatement costs of climate change in a perfectly competitive environment with perfect foresight 
(Weitzman 2012). IAMs form the bulk of research done on addressing policy goals like the 2 degree climate targets (IPCC 2012, 2016). While IAMs have been expanded considerably to include multiple sectors (Tol 1997), and regions (Nordhaus and Yang 1996; Nordhaus and Sztorc 2013; Hope 2013), they face rising criticism over a lack of discussion of the importance of non-competitive markets, path-dependencies, the role endogenous technological change, and the role of $R \& D$ and innovation, which can cause models to overstate the extent of climate damage (Stern 2016; Pindyck 2017).

This gap in the IAMs models is filled by endogenous technological models, which attempt to explain how factors like prices, investment levels, and $\mathrm{R} \& \mathrm{D}$, can help explain input-specific productivity gains within the model (Kennedy 1964; Binswanger and Ruttan 1978; Dosi 1988). A key theory behind this is the induced innovation hypothesis (Hicks 1932) which states that inputs with rising costs will see higher R\&D investment to improve input-specific productivity gains, which, for profit-maximizing firms, implies lower costs. Endogenous growth theory models, as formalized by Romer (1990), do away with the perfectly competitive markets and assume that firms invest in $R \& D$ to produce innovation, which enables them to create patent-driven monopolistic markets, allowing them to extract rents (Tavani and Zamparelli 2017). This theory, for example, has been used to explain that despite persistent labor productivity gains over the last century, wages have been rising, resulting in an upward sloping demand-curve (Acemoglu 1998, 2002).

Endogenous technological change climate models build on the Romer framework (Romer 1990) by introducing a low or zero-emissions "green" and a high-emissions "brown" sector, where the aim of the central planner is to transition towards a greener economy (Löschel 2002; Kahouli-Brahmi 2008; Gillingham et al. 2008; Popp et al. 2010). Within this field, the seminal contribution of Acemoglu et al. (2012) considerably expands the earlier research in this field (Smulders 1995; Bovenberg and Smulders 1996; Ferrante 1998) to show how climate policies can be introduced in a generic endogenous growth model. A growing body of literature in this field discusses various strands of assumptions, for example, the role of input substitutability, level of R\&D investment, the timing of policies, and whether to use market-based or "command-and-control"-based policy instruments (van der Zwaan et al. 2002; Carraro et al. 2003; Jaffe et al. 2003; Bretschger 2005; Lutz et al. 2005; Requate 2005; Popp 2006; Sue Wing 2006a; Kahouli-Brahmi 2008; Grimaud and Rouge 2008; Behar 2009; Windrum et al. 2009; Vona and Patriarca 2011; Acemoglu et al. 2012, 2016; Lamperti et al. 2016). ${ }^{2}$

These models also highlight the complexity of the problem with several avenues still open to further research. First, understanding and calculating the indirect effects of $R \& D$, which potentially materialize over a longer time horizon (Sveikauskas 2007; Grimaud and Rouge 2008). Second, understanding the role of

\footnotetext{
${ }^{2}$ See also, for example the ENTICE model, that introduces the endogenous technological change in the DICE framework (Popp 2004). Additionally, the WITCH CGE-IAM model (http://www.witchmodel.org/), that provides a rich combination of bottom-up energy supply decisions with top-down output optimal growth decisions with endogenous technological change (Bosetti et al., 2006, 2007; Carrara and Marangoni, 2017).
} 
the private and public sectors' contribution to $R \& D$ spending since their incentive structures vary. While the private sector aims at maximizing profits, the public sector aims at maximizing social welfare (Löschel 2002; Popp et al. 2010). Third, highlighting the impact of innovation in one input on other inputs, where the elasticity of substitution between the two can play an important role. These for example can result in "crowding-out", where R\&D investment is shifted towards a specific input leaving less for innovation in other inputs (Sue Wing 2006b; Pizer and Popp 2008; Popp et al. 2010; van den Bergh 2013), or "rebound effects" where lowering of costs increases demand (Binswanger 2001; Herring and Roy 2007; Otto et al. 2008). To tackle some of these questions, endogenous technological change climate models are also supported by a growing number of empirical papers, which usually investigate the direction and intensity of climate policies in inducing technological change towards a greener economy (Popp 2001, 2002; Lutz et al. 2005; Golec and Vernon 2010; Sue Wing 2006b; Aalbers et al. 2013; Eom et al. 2015; Aghion et al. 2016).

\subsection{Debates in Ecological Economics}

A core criticism of mainstream climate models comes from the recently flourishing field of Ecological Economics. The Ecological Economics discourse starts with the premise that the planetary boundaries need to be respected (Rockström et al. 2009; Steffen et al. 2015), and there are limits to growth such that once certain environmental tipping points are crossed, the consequences will be non-reversible (Meadows et al. 1972, 2004). Therefore one needs to find a balance between the use of natural resources and minimal societal needs to come up with equitable and "just" development pathways (Raworth 2017). The field is skeptical of the standard economic models, especially the IAMs, which only rely on supply-side pricing (Victor and Rosenbluth 2007; Spash 2012; Rezai and Stagl 2016; Røpke 2016) without discussing the role of path-dependencies and institutions that are central to overall societal transformations towards a low-carbon economy (Kronenberg 2010; Pollitt et al. 2010; Scrieciu et al. 2013; Rezai et al. 2013). Additional they also emphasize the role of finance and financial institutions in impacting investment decisions (Lavoie, 2014; Monasterolo and Raberto, 2018), and the role state, which both complements and competes with the private sector in terms of R\&D spending and innovation (Mazzucato, 2015, 2016).

Despite these criticisms, the field of ecological economics is agnostic about the right choice of modeling tools, and with polemic viewpoints ranging from "de-growth" (Victor 2012; Klitgaard and Krall 2012; Kallis et al. 2012), "a-growth" (Van den Bergh 2011; van den Bergh 2017), to more recent "post-growth" (Victor and Rosenbluth 2007) movements. These debates broadly mentions technological change and innovation as one of the drivers of green transition (Bretschger 2005; Cato 2012; Scrieciu et al. 2013; van den Bergh 2013) but the limited pool of non-mainstream models that deal with climate change are still a step away from fully incorporating these concepts within their modeling frameworks. 


\subsection{Non-mainstream approaches}

Non-mainstream ecological macromodels are a relatively new field, mainly due to the fact that supply-side environmental constraints have not been a concern in a primarily demand-driven field (Kronenberg 2010; Rezai et al. 2013; Fontana and Sawyer 2013, 2016). These models use alternative model closures, focusing on the demand and investment side of the economy, while also addressing endogenous institutional change (Lavoie 2014). This implies a stronger role of both financial sectors and the government as key players in policy outcomes. Several modeling approaches exist within this field: analytical demand-driven models (Fontana and Sawyer 2016; Rezai et al. 2018), agent-based models (ABMs) that exploit properties of a large continuum of heterogeneous agents (Balint et al. 2017), and a newer pool of accounting-based Stock-Flow Consistent (SFC) macro models that carefully analyze the impact of climate policies given financial and institutional constraints (Hardt and O'Neill 2017).

\subsubsection{Analytical post-Keynesian models}

The post-Keynesian framework is significantly different from neo-classical framework in its rejection of the Say's Law, despite having growth and investment as central themes (Lavoie 2014). At the core of postKeynesian models are two key assumptions. First, is fundamental uncertainty where future outcomes are unknown resulting in adaptive behavioral heuristics that can be modeled through adaptive expectations or herding behavior (as opposed to rational expectations in mainstream models). As a consequence, agents update their behavior based on past experiences, current market signals, and future expectations. In this scenario, one moves away from optimal inter-temporal allocation of resources to path-dependent outcomes. Second, capital stock and employment, are in general, not at their optimal level allowing the economy the flexibility to adjust to fluctuations both in the short and in the long-run (Robinson 1956; Kaldor 1957; Kalecki 1971).

While both endogenous growth models and post-Keynesian models emphasize mechanisms that give rise to path-dependent growth, the post-Keynesian school goes a step further to include endogenous institutional change as well, for example hysteresis effects on the labor markets (Setterfield 2011; Stockhammer 2011). Under these assumptions, the implications for R\&D investment are significantly different. This implies that investment in resource-saving technologies might be competing with the dominant labor sector mostly driven by the structure of the labor markets, for example, due to the presence of union bargaining processes or endogenous social wage norms, that constantly put an upward pressure on the labor share in output.

In post-Keynesian models, technological change is introduced as either as constant factor of time or using the Verdoorn's law (Verdoorn 1980), which hypothesizes that innovation and productivity go up as demand increases through either learning-by-doing effects or increasing returns-to-scale production functions (Lavoie 2014). The Verdoorn's law complements the post-Keynesian theory as it ensures that the demand shocks shift aggregate demand as well as aggregate supply (Kaldor 1957; Dutt 2006; Bhaduri 2006). Recent 
papers also attempt to endogenize technological change from a non-mainstream perspective, for example by modeling labor productivity growth as a function of capital accumulation, income distribution, and labor market tightness (Foley and Michl 1999; Tavani 2012; Zamparelli 2015; Tavani and Zamparelli 2017)

Ecological macro models stemming from the post-Keynesian school are a relatively new field (Hardt and O'Neill 2017). Within these small pool of models, technological change and innovation, are introduced as broad concepts without discussing mechanisms in detail (Kronenberg 2010; Fontana and Sawyer 2013, 2016). Models introduce productivity parameters as either constants (Victor 2008; Jackson 2009; Berg et al. 2015; Naqvi 2015) or linearly increasing over time (Fontana and Sawyer 2013, 2016; Dafermos et al. 2017).

\subsubsection{Agent-based models}

Agent-based models (ABMs) are a bottom-up modeling technique where interactions across large continuum of agents results in meso and macro outcomes (Arthur 1999; Axtell 2000; Tesfatsion 2006). A key advantage of ABMs is their ability to handle out-of-equilibrium states, non-linear interactions, and ability to incorporate learning and evolutionary behavior that can give rise to non-linear outcomes that standard models are not able to handle (Axtell 2003; Gilbert 2008). After the 2008 financial crisis, ABMs have become an important tool for modeling and analyzing the complexity of financial interactions (Farmer and Foley 2009) mostly focusing on the aspects of an endogenous system collapse using a complexity approach (Dosi et al. 2010; Battiston et al. 2012; Thurner and Poledna 2013; Dosi et al. 2013; Monasterolo and Raberto 2018).

In climate economics, ABMs, have been referred to as the "third wave" (Farmer et al. 2015) filling in the gaps created by mainstream models and addressing the complexities that can arise from interaction of heterogeneous firms, households, and banks. Balint et al. (2017) reviews the key strands of ABMs where in the macro models domain, ABMs predominantly expand existing IAMs by introducing a large set of heterogeneous agents to analyze distributional impacts of climate policies in a limited information environment (Haas and Jaeger 2005; Gerst et al. 2013; Rengs et al. 2015; Safarzyńska and van den Bergh 2017; Lamperti et al. 2017). Lamperti et al. (2018) reviews the climate ABM literature and discusses the limitations of existing models, including the analysis of extreme events and climate policies in current models. They suggest that extreme events can result in fat-tailed distributions and non-equilibrium states where a bottom-up heterogeneous agent approach can help understand the distributional aspects of climate change and climate policies. Lamperti et al. (2018) also propose modeling frameworks that can help solve this problem but highlight that more research is required on distributions, finances, and climate policies.

ABMs usually introduce innovation in a Schumpeterian framework (Schumpeter 1934; Nelson and Winter 1982) and couple it with Keynesian dynamics (Dosi et al. 2010, 2013; Rengs et al. 2015). Within this framework, heterogeneous firms are endowed with probabilistic functions to innovate, where another set of probability distributions determine how much gets diffused, adapted, and replicated in a network dynamics- 
type setting. ${ }^{3}$

While ABMs are strong tool for exploring high levels of complexities, especially of the type that exist in coupled economic-environment systems, they also have several drawbacks. ABMs, usually operate with a very large parameter space making calibrations difficult. Furthermore, a large pool of heterogeneous agents within different institutional classes considerably increases the complexity of interactions making the results less tractable.

\subsubsection{Stock-flow consistent (SFC) Macromodels}

Stock-flow consistent (SFC) models stem from the post-Keynesian school (e Silva and dos Santos 2011; Caverzasi and Godin 2015; Nikiforos and Zezza 2017) and employ a national systems of accounts of approach to represent the interactions of economic sectors. The sectors are usually represented as Households, Firms, Government, Banks, where each sector is endowed with its own set of behavioral rules. SFC models were first introduced in the early 1940s, to study the role of money in the Flow of Fund accounts of central banks (Copeland 1949; Cohen 1972) and were later expanded to understand current monetary systems focusing on endogenous money theory and banking regulations (Godley and Lavoie 2007; Lavoie and Godley 2012). They gained high traction post-2008 financial crisis, especially with their ability to incorporate business cycles, effectively challenging the pre-dominant viewpoint of "efficient market hypothesis" under which financial collapse cannot occur (van Treeck 2009).

SFC models uses a balance sheet approach with a quadruple-entry accounting framework that tracks stocks and flows across and within sectors. A key strength of this approach is that it ensures that interactions across and within sectors result in zero-sum transactions. Therefore, by construction, changes triggered in one sector due to a policy, feedback across other sectors to balance the accounting identities (dos Santos and Zezza 2008; Caverzasi and Godin 2015). These feedback loops, resulting from a zero-sum condition, are of key interest in this paper, where we aim to highlight how economic conditions affect investment decisions, and subsequently innovation when facing a budget constraint where crowding-out (Löschel 2002; Popp 2006) and rebound effects (Otto et al. 2008) can be systematically analyzed. By construction, SFC models can be placed in the middle of analytical models with a small parameter space and agent-based models which operate with a large parameter space. This provides a medium level of complexity that allows for easy tractability, even allowing analytical solutions to be derived for relatively large models (Zezza 2003).

SFC models have also been employed to study the impact of climate policies by coupling economic accounts with environmental accounts (Jackson et al. 2015; Naqvi 2015; Hardt and O'Neill 2017). They have also been extended to include environmental boxes used in standard climate models (Dafermos et al. 2017), input-output analysis to incorporate material flows (Berg et al. 2015), and multi-regional analysis in

\footnotetext{
${ }^{3}$ See, for example, the Journal of Evolutionary Economics, that specializes on applications of Schumpeterian innovation.
} 
a North-South framework (Dunz and Naqvi 2017). SFC models have also been recently extended to a new branch of SFC-ABM models where stock-flow norms govern a large set heterogeneous agents (Monasterolo and Raberto 2018) within each sector, for example, to analyze policies across EU member states (Caiani et al. 2016, 2018).

While, on the one hand, SFC models are a relatively new unexplored methodology that provides a rich framework for analyzing environmental policies, on the other hand, they lack an extensive treatment of climate problems, aspects of endogenous technological change, and climate-financial linkages that provide a strong avenue for future research.

\section{The Model}

The model is set up using four sectors typically represented in the national system of accounts maintain by central banks; a firm sector which produces all the goods in the economy, a household sector, further divided into workers and capitalists that provide labor and capital respectively, a government sector, which collects tax revenue and spends it on public consumption and investment decision, and a banking sector, which hold household deposits and give out loans to firms.

In order to keep the model tractable, several simplifying assumptions are introduced. First, the firm sector produces both consumption and capital goods. Additionally, the firm sector also produces R\&D, as part of the general investment demand. $R \& D$ is financed through the firm sector's profitability and government sector's general expenditure decisions. The government targets a balanced budget by adjusting its variable expenditure and thereby acts pro-cyclical. Since both firms and the government are affected by macro trends, $R \& D$ investment is also cyclical.

The firm sector uses three inputs - Labor, Capital, and Resources - to meet the final demand. The Resource input in the model broadly represents material and energy requirements of the economy. This is a simpler specification than standard models, where the distinction is usually made between "green" and "brown" firms, typically introduced as two separate sectors (see Monasterolo and Raberto 2018 for an application in an SFC framework). Our approach avoids expanding the balance sheet to include two firm sectors in the SFC framework. Instead Resources are introduced as a generic input in the production function. Therefore, a growth of the green sector relative to the brown sector is reflected in a decrease in resource intensity.

We assume a closed monetary circuit which allows us to link financial flows generated within the model through interactions across the sectors. The Household sector earns profit and wage income and interest on savings held in banks. We also introduce labor institutions that index wage growth to past economic performance and target wage share constantly putting an upward pressure on wages. Banks are introduced as simple intermediaries and the environmental sector simply reports the direct emissions resulting from 
output and Resource use.

Table 3.1 shows the Transition Flow Matrix (TFM) which records all the flows across and within the four sectors of the economy. All rows and columns represent accounting identities which by definition sum up to zero. For example, in the first column, workers earn wage income $(W B)$ and interest income on deposits $\left(r_{d} D_{t-1}^{W}\right)$, pay taxes $\left(T^{W}\right)$, consume goods $\left(C^{W}\right)$, and then adjust the remaining money as bank deposits $\left(\Delta D^{W}\right)$, resulting in a change in the stock of wealth at the end of the year. Similarly, capitalists earn dividend income from firms $(D i v)$, profit income from banks $\left(\Pi^{B}\right)$, and resource rents $\left(\Pi_{t}^{R}\right)$. Like workers, they also earn interest on past deposits $\left(r_{d} D_{t-1}^{K}\right)$.

The rows highlight the interactions across institutional sectors. For example, the first row shows the consumption expenditure of households $\left(C^{W}+C^{K}\right)$ that is fully met by firms $(C)$. The second row the shows the government expenditure $(G)$, and the third row the investment $(I)$. The first three rows define the core identity of the economy which can be summarized in Equation 1 as:

$$
Y_{t}=C_{t}+I_{t}+G_{t}
$$

where the total output or GDP $Y_{t}$, equals household consumption $C_{t}$, investment $I_{t}$, and government expenditure $G_{t}$.

Table 3.1: Transition Flow Matrix (TFM)

\begin{tabular}{|c|c|c|c|c|c|c|c|}
\hline & \multicolumn{2}{|c|}{ Households } & \multicolumn{2}{|c|}{ Firms } & \multirow[t]{2}{*}{ Banks } & \multirow[t]{2}{*}{ Govt } & \multirow[t]{2}{*}{ Total } \\
\hline & Workers & Capitalists & Current & Capital & & & \\
\hline Consumption & $-C_{t}^{W}$ & $-C_{t}^{K}$ & $+C_{t}$ & & & & 0 \\
\hline Government & & & $+G_{t}$ & & & $-G_{t}$ & 0 \\
\hline Investment & & & $+I_{t}$ & $-I_{t}$ & & & 0 \\
\hline$(R \& D)$ & & & $\left(+R \& D_{t}\right)$ & $\left(-R \& D_{t}^{F}\right)$ & & $\left(-R \& D_{t}^{G}\right)$ & 0 \\
\hline Wages & $+W B_{t}$ & & $-W B_{t}$ & & & & 0 \\
\hline Resources & & $+\Pi_{t}^{R}$ & $-R B_{t}$ & & & $+T_{t}^{R}$ & 0 \\
\hline Loan repay. & & & & $-\beta L N_{t-1}$ & $+\beta L N_{t-1}$ & & 0 \\
\hline Profits & & $+\operatorname{Div}_{t}+\Pi_{t}^{B}$ & $-\Pi_{t}^{F}$ & $+R \& D_{t}^{F}$ & $-\Pi_{t}^{B}$ & & 0 \\
\hline Taxes & $-T_{t}^{W}$ & $-T_{t}^{K}$ & $-T_{t}^{F}$ & & $-T_{t}^{B}$ & $+T_{t}$ & 0 \\
\hline$i$ Deposits & $+r_{d} D_{t-1}^{W}$ & $+r_{d} D_{t-1}^{K}$ & & & $-r_{d} D_{t-1}$ & & 0 \\
\hline$i$ Loans & & & $-r_{l} L N_{t-1}$ & & $+r_{l} L N_{t-1}$ & & 0 \\
\hline$\Delta$ Deposits & $-\Delta D_{t}^{W}$ & $-\Delta D_{t}^{K}$ & & & $+\Delta D_{t}$ & & 0 \\
\hline$\Delta$ Loans & & & & $+\Delta L N_{t}$ & $-\Delta L N_{t}$ & & 0 \\
\hline Total & 0 & 0 & 0 & 0 & 0 & 0 & 0 \\
\hline
\end{tabular}


Two additional features are introduced in Table 3.1 over a standard SFC model (Lavoie and Godley 2012). First, Resources are assumed to be privately owned by Capitalists extract Resource rents $\left(\Pi_{t}^{R}\right)$, determined by firm's Resource bill $\left(R B_{t}\right)$, after paying a Resource tax $\left(T_{t}^{R}\right)$. Second, firms produce R\&D, a subset of investment, which is financed by the private sector's own $R \& D$ contribution $\left(R \& D_{t}^{F}\right)$, and government's public expenditure $\left(R \& D_{t}^{G}\right)$.

For the sake of clarity, several notations are introduced. The subscript $t$ represents variables that are updated every point in time. Greek letters represent calibration parameters. Capital letters with subscript $t$ represent nominal values, for example nominal output equals $Y_{t}$, while small letters with subscript $t$ represent real values, for example real output equals $y_{t}$. Simulation runs are presented for a total of 50 years.

\subsection{Firms}

Firms produce all consumption and capital goods demanded within the economy. Input requirements are based on the real output $y_{t}=Y_{t} / p_{t}$ and are determined by a Leontief production function using three inputs: ${ }^{4}$

$$
y_{t}=\min \left[L_{t}, K_{t}, R_{t}\right]
$$

where the quantity of three complementary inputs, Labor $(L)$, Capital $(K)$, and Resources $(R)$ are determined by their relative productivities:

$$
L_{t}=\frac{y_{t}}{\epsilon_{t}^{L}}, K_{t}=\frac{y_{t}}{\epsilon_{t}^{K}}, R_{t}=\frac{y_{t}}{\epsilon_{t}^{R}}
$$

The Leontief function represents the production function typically used in post-Keynesian models, where a fix-coefficient input technology is required to produce a unit of output. This is a simplifying assumption where a complete model would allow for the ex-ante production technology to be substitutable, however ex-post, once a certain technology has been selected, substitution is difficult and the production is thus proxied by a Leontief technology (Koesler and Schymura 2015). This also allows for under-utilization of labor and capital technologies allowing for supply adjustments based on changes in demand. In our model, production coefficients across the three inputs will vary over time due to endogenous technological progress, thus our model allows for substitution in a dynamic sense. ${ }^{5}$

\section{Labor costs}

Total labor demand and the wage bill are determined as follows:

\footnotetext{
${ }^{4}$ See Kümmel et al. (2015); Voudouris et al. (2015) for a discussion on using energy and resources as a third input in standard climate models.

${ }^{5}$ See Appendix B for the CES input demand function case.
} 


$$
\begin{aligned}
L_{t} & =\frac{y_{t}}{\epsilon_{t}^{L}} \\
W B_{t} & =p_{t}^{L} L_{t}
\end{aligned}
$$

The price of labor is the wage rate $p_{t}^{L}$ paid per unit of output produced. Average wages in the model are determined by past wage growth rates and union bargaining processes that mimic labor market hysteresis (Skott 2006; Stockhammer 2011). The wage dynamics are described as follows:

$$
\begin{aligned}
\dot{p}_{t}^{L} & =\gamma_{\omega} \dot{p}_{t-1}^{L}+\gamma_{W}\left(\Omega_{t}^{T}-\Omega_{t-1}\right) \\
\Omega_{t}^{T} & =\Omega_{t-1}^{T}+\gamma_{\Omega}\left(\Omega_{t-1}-\Omega_{t-1}^{T}\right) \\
\Omega_{t} & =\frac{W B_{t}}{Y_{t}}
\end{aligned}
$$

Wage growth $\dot{p}_{t}^{L}$ (Eq. 6) is determined as a function of past wage growth rate $\dot{p}_{t-1}^{L}$, highlighting the inertia from past wage increases. The second part of Eq. 6 , shows the gap between the target wage share $\Omega_{t}^{T}$ and the past wage share $\Omega_{t-1}$, where wage share is defined as the total wage bill over GDP (Eq. 8). $\gamma_{\omega}$ and $\gamma_{W}$ represent the relative adjustment weights. Therefore, if wages have been previously rising, and if the current wage share (Eq. 8) is below that target wage shares, wages will continue to rise due to endogenous wage norms. The target wage share $\Omega_{t}$ (Eq. 7) is updated based on past wage share trends. Skott (2006) and Stockhammer (2008) demonstrate that this is sufficient to generate an endogenous NAIRU and hysteresis in wages and unemployment. If the economy is in long periods of slump, the target also falls implying that workers and unions ultimately lower their expectations over time. $\gamma_{\omega}$ represent the degree of hysteresis and ensures that the natural rate of unemployment is endogenous in the long run.

\section{Resource costs}

Resources represent non-renewable inputs in the production process and are assumed to be owned by capitalist households. Like Labor and Capital, the firm's demand for Resources $\left(R_{t}\right)$ is determined by it level of productivity $\epsilon_{t}^{R}$ (Eq. 9):

$$
\begin{aligned}
R_{t} & =\frac{y_{t}}{\epsilon_{t}^{R}} \\
p_{t}^{R} & =\bar{p}^{R}\left(1+\tau^{R}\right) \\
R B_{t} & =p_{t}^{R} R_{t} \\
\Pi_{t}^{R} & =R B_{t}-T_{t}^{R} \\
T_{t}^{R} & =R_{t} \bar{p}^{R} \tau^{R}
\end{aligned}
$$


For the sake of simplicity, we assume that Resources exist in abundance and have a fixed per unit production cost $\bar{p}^{R}$. The price of a unit of Resource $p_{t}^{R}$ (Eq. 10) is estimated as the base price times the Resource tax, $\tau^{R}$. The total Resource bill, $R B_{t}$ (Eq. 11), equals the resource demand times the price. The total resource tax revenue $T_{t}^{R}$ is given in Eq. 13. Rents earned from Resources $\Pi_{t}^{R}$ go to capitalist households as income (Eq. 12) calculated as reveue $R B_{t}$ (Eq. 11) net of taxes $T_{t}^{R}$ (Eq. 13).

\section{Capital costs, investment, and loans}

We use a simple investment function, which has as its central feature that investment is demand-driven. Capital formation takes place through investment decisions where the target real capital stock $k_{t}^{T}$, is determined by the capital productivity level $\epsilon_{t}^{K}$ :

$$
k_{t}^{T}=\frac{y_{t}}{\epsilon_{t}^{K}}
$$

Assuming capital depreciates at a rate $\delta$, the current Capital stock $k_{t}$ is determined as the past Capital stock adjusted for depreciation plus investment $i_{t}$ :

$$
k_{t}=k_{t-1}(1-\delta)+i_{t}
$$

The investment function is derived as:

$$
\begin{aligned}
& i_{t}=\gamma_{i}\left(k_{t}^{T}-k_{t-1}\right)+\delta k_{t-1} \\
& I_{t}=i_{t} p_{t}+R \& D_{t}^{F}
\end{aligned}
$$

where real investment $i_{t}(\mathrm{Eq}$. 16) is a fraction of the gap between the target capital stock and the past capital stock, closed at a rate $\gamma_{i}$, plus capital stock replacement resulting from depreciation. Nominal investment, $I_{t}$ (Eq. 17), equals Capital investment $\left(i_{t} p_{t}\right)$ plus the R\&D expenditure $\left(R \& D_{t}^{F}\right)$ undertaken by firms (see Sec. 3.6 for the derivation of R\&D).

Firm's investment in Capital stock is fully supported by loans $\left(L N_{t}\right)$ from banks. Although, this is a simplistic assumption, since firms can also self-finance investment through retained earnings, it does not effect the model results. In principle higher dividends to capitalists imply that capitalists save more in banks giving banks more liquidity to lend out new loans, especially at very low borrowing interest rates.

The total current loan demand $\left(L N_{t}\right)$ equals:

$$
L N_{t}=L N_{t-1}(1-\beta)+I_{t}
$$

where $\beta$ is the loan repayment rate. 


\section{Prices and profits}

Firms use mark-up pricing over unit costs (Kalecki 1971) where the burden of the tax is fully shifted on to the consumers. Unit costs are calculated as the sum of the three input costs; the wage bill $\left(W B_{t}\right)$, the Resource bill $\left(R B_{t}\right)$, plus the interest and repayment of past loans $\left(\left(r_{l}+\beta\right) L N_{t-1}\right)$, divided by the total real output $\left(y_{t}\right)$ :

$$
U C_{t}=\frac{W B_{t}+R B_{t}+\left(r_{l}+\beta\right) L N_{t-1}}{y_{t}}
$$

Unit costs contribute to the prices, where the target price $p_{t}^{T}$ equals:

$$
\begin{aligned}
p_{t}^{T} & =U C_{t}(1+\theta)\left(1+\tau^{F}\right) \\
p_{t} & =p_{t-1}+\gamma_{p}\left(p_{t}^{T}-p_{t-1}\right)
\end{aligned}
$$

In Equation 20, $\theta$ is the mark-up value on costs, where a higher value of $\theta$ represents a higher monopoly power of firms. $\tau^{F}$ is the profit tax. Prices update at a rate $\gamma_{p}$ (Eq. 21) implying sticky price adjustments.

Profits of the firm $\left(\Pi_{t}\right)$ can be derived as:

$$
\begin{aligned}
& \Pi^{F}=Y_{t}-T_{t}^{F}-W B_{t}-R B_{t}-\left(r_{l}+\beta\right) L N_{t-1} \\
& T_{t}^{F}=\left(Y_{t}-W B_{t}-R B_{t}-\left(r_{l}+\beta\right) L N_{t-1}\right) \tau^{F}
\end{aligned}
$$

Following the general consensus in literature, that private $\mathrm{R} \& \mathrm{D}$ decisions are directly linked to firm profitability and economic growth (Audretsch 1995; Dosi 1988; Guellec and van Pottelsberghe de la Potterie 2003; Golec and Vernon 2010; Sue Wing 2006a; Karjalainen 2008; Aghion et al. 2012; Minniti and Venturini 2017), we replicate this in the model by assuming that a fraction of profits are invested in private $R \& D$ such that:

$$
\begin{aligned}
R \& D_{t}^{F} & =\mu \Pi_{t}^{F} \\
D i v_{t} & =(1-\mu) \Pi_{t}^{F}
\end{aligned}
$$

The remaining profits go to the capitalists as dividend income, Div $($ Eq. 25).

\subsection{Households}

Households are split into two categories, Workers $(W)$ and Capitalists $(K)$. Both classes earn income from different sources: 


$$
\begin{aligned}
& I n c_{t}^{W}=W B_{t}+r_{d} D_{t-1}^{W} \\
& \operatorname{Inc}_{t}^{K}=D i v_{t}+\Pi_{t}^{B}+\Pi_{t}^{R}+r_{d} D_{t-1}^{K}
\end{aligned}
$$

Workers earn (Eq. 26) wage income $W B_{t}$ plus interest on their past deposits $r_{d} D_{t-1}^{W}$. Capitalists earn (Eq. 27) dividend income, $D i v_{t}$, from firms, profit income, $\Pi_{t}^{B}$, from banks plus rents from selling Resources $\Pi_{t}^{R}$. Like workers, they also earn interest income on their past deposits $r_{d} D_{t-1}^{K}$.

For simplicity, the behavior rules of the two classes is assumed homogenous. Assuming the Household sectors can be indexed as $j=W, K$, the behavioral rules of the $j$ sectors can be described by the following generic set of equations:

$$
\begin{aligned}
T_{t}^{j} & =\tau^{H} \operatorname{Inc}_{t}^{j} \\
Y D_{t}^{j} & =\operatorname{Inc} c_{t}^{j}-T_{t}^{j} \\
C_{t}^{j} & =\alpha_{1} Y D_{t}^{j}+\alpha_{2} D_{t-1}^{j} \\
D_{t}^{j} & =D_{t-1}^{j}+\left(Y D_{t}^{j}-C_{t}^{j}\right)
\end{aligned}
$$

Eq. 28 gives the income tax $\left(T_{t}^{j}\right)$ calculation on the household income at a rate $\tau^{H}$. Eq. 29 gives the disposable income $\left(Y D_{t}^{j}\right)$, or income minus taxes. Eq. 30 describes the consumption $\left(C_{t}^{j}\right)$ decision of the households which is determined by the marginal propensity to consume out of income $\alpha_{1}$, and the marginal propensity to consume out of past deposits $\alpha_{2}$. Eq. 31 shows the change in deposits $\left(D_{t}^{j}\right)$, which equals the opening deposit balance plus savings which equal disposable income $\left(Y D_{t}^{j}\right)$ minus consumption $\left(C_{t}^{j}\right)$.

A richer analysis would imply different parameters across different household classes allowing for exploring the distributional impacts of climate policies.

\subsection{Banks}

Commercial banks are a passive entity in the model playing the role of intermediaries between households and firms. Banks earn income through interest earnings from loans $\left(r_{l}\right)$ less interest paid out to household on deposits $\left(r_{d}\right)$. Since the model is SFC, loans and deposits should equalize in the long-run. As long as $r_{l} \geq r_{d}$, banks will earn profits. Banks profits $\Pi_{t}^{B}$ (Eq. 32) are therefore derived as interest earnings net of taxes (Eq: 33):

$$
\begin{aligned}
& \Pi_{t}^{B}=r_{l} L N_{t-1}-r_{d}\left(D_{t-1}^{W}+D_{t-1}^{K}\right)-T_{t}^{B} \\
& T_{t}^{B}=\left(r_{l} L N_{t-1}-r_{d}\left(D_{t-1}^{W}+D_{t-1}^{K}\right)\right) \tau^{B}
\end{aligned}
$$


where banks pay a tax rate $\tau^{B}$ on profits.

As the focus of the paper is endogenous technical change in a post-Keynesian SFC model, we purposefully keep the financial sector simple. This is for the sake of tractability, not realism. In particular we sidestep issues of credit rationing credit rationing and financial instability (Nikolaidi and Stockhammer 2017; Monasterolo and Raberto 2018; Caiani et al. 2018).

\subsection{Government}

In the model, the government subsumes the role of the central bank. The government flows comprise of tax revenues which are balanced by government's variable spending. In the model we assume a conservative balanced-budget government in line with the official policies in the EU, for example, the Maastricht Treaty, which limits deficit spending.

Assuming the government has a fixed minimum expenditure $\bar{G}$, its balance can be written:

$$
B a l_{t}=\bar{G}-T_{t}
$$

where $T_{t}=T_{t}^{W}+T_{t}^{K}+T_{t}^{F}+T_{t}^{R}+T_{t}^{B}$ represents the overall tax revenue. In order to have a zero balance $\left(\mathrm{Bal}_{t}=0\right)$, the government adjusts its variable expenditure $G_{t}^{\text {var }}$

$$
G_{t}^{v a r}=G_{t-1}^{v a r}+\gamma_{g}\left(B a l_{t}-G_{t-1}^{v a r}\right)
$$

at a rate $\gamma_{g}$, where a low value of $0 \leq \gamma_{g} \leq 1$ implies lags in slowing down of government expenditure in a downturn. Total government expenditure can be derived as:

$$
G_{t}=\bar{G}+G_{t}^{v a r}
$$

The share of government spending on $\mathrm{R} \& \mathrm{D}$ is set as a fraction $\psi$ of its variable expenditure $G_{t}^{v a r}$ such that:

$$
R \& D_{t}^{G}=\psi G_{t-1}^{v a r}
$$

making public R\&D cyclical to economic outcomes.

A richer government sector would include issuing of bonds (including green bonds) to balance the government budget, and an independent Central Bank (Lavoie (2014) chap 11), which will allow for testing of green monetary and fiscal policies. 


\subsection{Environment}

In economic models, the environment is usually modeled as a "climate box" with multiple components (Nordhaus 1994; Weitzman 2012). The core assumption behind the climate box is that economic output increase emissions, causing temperatures to rise, resulting in higher radiative forces. Some models also introduce full carbon cycles from the environmental sciences domain which features upper and lower atmospheres, land-use change, forests, and ocean temperatures (Nordhaus and Sztorc 2013). Collectively these components of the environment affect the economy through a "damage function" that directly affect capital, output, or labor productivity. Within SFC models, notable applications include Dafermos et al. (2017), which replicates the Nordhaus and Sztorc (2013) carbon cycles, and Berg et al. (2015), which incorporates a detailed input-output material flow analysis.

In the model, we keep the climate box minimalistic, simply focusing on direct emissions related to output and Resource use. An emissions function is defined as:

$$
E m m_{t}=E m m_{t-1}+\frac{y_{t}+R_{t}}{\epsilon^{G}}
$$

Equation 38 implies that emissions rise based on overall real output and Resource use where $\epsilon^{G}$ is the constant emissions-to-output ratio.

\subsection{Research and Development (R\&BD)}

The investment decision in inputs follow the induced innovation hypothesis (Hicks 1932; Romer 1990; Acemoglu 2002), where the relatively more expensive input sees higher R\&D investment, resulting in higherthan-usual productivity gains. While on the one hand, the induced innovation hypothesis has been modeled and tested extensively in mainstream literature with a focus on price related market mechanisms for a green transition (Newell et al. 1999; Popp et al. 2010), on the other hand, little is discussed about the role of limited finance on such investment decisions (Sveikauskas 2007). This is even more pertinent now, where firms, following the 2008 financial crisis, are cautious about investing in riskier technologies (Monasterolo and Raberto 2018). In such a scenario, limited investment is likely to go the most expensive input, which historically has been labor. To deal with this challenge, we suggest that R\&D investment decision in complementary, yet competing inputs, can be modeled as a portfolio choice allocation problem, similar to the one developed in Tobin (1982) and extensively used in financial portfolio choice models in SFC models (van Treeck 2009; Lavoie and Godley 2012; Caverzasi and Godin 2015). This allows us to have heterogeneous treatments of the three inputs in the allocation of the R\&D budget. This is formalized as follows:

Total R\&D expenditure equals private firm expenditure $R \& D_{t}^{F}$ (Eq. 24) and public $R \& D_{t}^{G}$ (eq. 37) expenditure such that $R \& D_{t}=R \& D_{t}^{F}+R \& D_{t}^{G}$. The government exogenously allocates investment shares across the three inputs $\left(\lambda_{1 G}, \lambda_{2 G}, \lambda_{3 G}\right)$. Firms similarly have a baseline autonomous investment allocation 
across the three inputs $\left(\lambda_{10}, \lambda_{20}, \lambda_{30}\right)$ plus additional adjustments based on relative price growth signals. This can be summarized in a matrix form:

$$
\left(\begin{array}{c}
R \& D_{t}^{L} \\
R \& D_{t}^{K} \\
R \& D_{t}^{R}
\end{array}\right)=\left(\begin{array}{c}
\lambda_{1 G} \\
\lambda_{2 G} \\
\lambda_{3 G}
\end{array}\right) R \& D_{t}^{G}+\left[\left(\begin{array}{c}
\lambda_{10} \\
\lambda_{20} \\
\lambda_{30}
\end{array}\right)+\left(\begin{array}{ccc}
\lambda_{11} & \lambda_{12} & \lambda_{13} \\
\lambda_{21} & \lambda_{22} & \lambda_{23} \\
\lambda_{31} & \lambda_{32} & \lambda_{33}
\end{array}\right)\left(\begin{array}{c}
\dot{p}_{t}^{L} \\
\dot{p}_{t}^{K} \\
\dot{p}_{t}^{R}
\end{array}\right)\right] R \& D_{t}^{F}
$$

where $\dot{p}_{t}^{L}, \dot{p}_{t}^{K}, \dot{p}_{t}^{R}$ are the growth rates of prices of Labor, Capital, and Resources costs respectively. The price of capital we simply defined as the interest rate paid on the investments or $p_{t}^{K}=r_{l t}$. The above portfolio choice problem is subject to adding up constraints such that vertical summation of the first and second columns must add up to one. For example, $\lambda_{10}+\lambda_{20}+\lambda_{30}=1$ implying the budget is fully exhausted. The rows and columns of the $3 \times 3$ matrix must add up to zero, for example $\lambda_{11}+\lambda_{21}+\lambda_{31}=0$ and $\lambda_{11}+\lambda_{12}+\lambda_{13}=0$. This implies that an increase in investment in one input is taken out from the other two inputs, crowding-out their potential productivity growths. Additionally, symmetry conditions are also imposed on the matrix, for example $\lambda_{12}=\lambda_{21}$, which highlights the cross investment sensitivity of one input on another input.

Assuming that $m$ represents the index of three inputs such that $m=\{L, K, R\}$, the above formulation can be simplified as share of investment in each factor input as:

$$
\phi_{t}^{m}=\frac{R \& D_{t}^{m}}{R \& D_{t}}
$$

Since the system in Equation 39 is fully consistent, if two factor share are estimated, the third can be derived as a residual. For example, if $\phi_{t}^{L}$ and $\phi_{t}^{R}$ are known, then $\phi_{t}^{K}=1-\phi_{t}^{L}-\phi_{t}^{R}$.

Next we assume that the allocation of Resource across the three inputs determines their level of productivity gain determined as a difference between a target productivity $\epsilon_{t}^{m T}$ and past productivity $\epsilon_{t-1}^{m}$ :

$$
\epsilon_{t}^{m}=\epsilon_{t-1}^{m}+\gamma_{m}\left(\epsilon_{t}^{m T}-\epsilon_{t-1}^{m}\right)
$$

$\epsilon_{t}^{m T}$ is the target productivity growth estimated as function of the share of R\&D investment in Resource $m$ times the relative size of overall R\&D-to-GDP (R\&D intensity).

$$
\epsilon_{t}^{m T}=\epsilon_{t-1}^{m}\left(1+\phi_{t}^{m}\right)\left(1+\frac{R \& D_{t}}{Y_{t}}\right)
$$

The key assumption here is that higher R\&D spending relative to output increases overall productivity growth, while a higher share of investment in an input relative to the overall $R \& D$ budget gives an additional boost to productivity gains. 


\section{Policy simulations}

Two policy experiments are conducted in this paper. Experiment 1 shows how the government uses taxation to induce private firms to change their R\&D behavior. We contrast a one-off increase in the Resource $\operatorname{tax}\left(\tau^{R}\right)$ (RTax1) to a gradual but continuous increase $(R \operatorname{Tax}+)$, such that both tax scenarios are equal at the 20 year mark, but $R T a x+$ continues to rise throughout the 50 year simulation period. In Experiment 2, the government autonomously increases the share of public R\&D towards Resources from $33 \%$ to $80 \%(R \mathscr{E} D+)$. This experiment is then coupled with the RTax+ to assess the impact of the dual policies on the economy within the stock-flow consistent norms.

The business-as-usual (BAU) scenario is calibrated using the parameter values given in Appendix A. The parameters are in line with what is typically found in literature. MPC out of income $\left(\alpha_{1}\right)$ is 0.75 while MPC out of wealth $\left(\alpha_{2}\right)$ is set to 0.05. Households, Firms, and Banks pay income and profit taxes $\left(\tau^{H}, \tau^{F}, \tau^{B}\right)$ respectively at a rate of $20 \%$. In addition, Capitalist households pay a $5 \%$ Resource tax $\left(\tau^{R}\right)$. Markup value $(\theta)$ for firms is set at $10 \%$ and the loan repayment rate $(\beta)$ is $5 \%$. Banks charge a higher interest on loans $\left(r_{l}\right)$ at a rate of $0.2 \%$ while they pay households interest on deposits $\left(r_{d}\right)$ at a rate of $0.1 \%$. The government spends $1.5 \%$ of its variable expenditure on public R\&D $(\psi)$ while firms spend $20 \%$ of its profits, on private R\&D. The government allocates all of its R\&D equally across the three inputs $\left(\lambda_{1 G}=\lambda_{2 G}=\lambda_{3 G}=0.33\right)$, while firms have a higher baseline investment level for Labor, its most expensive input $\left(\lambda_{10}=0.70, \lambda_{20}=\lambda_{30}=0.15\right)$.

\subsection{Experiment $1-A$ Resource tax increase}

The first experiment showcases the impact of market-based policies, for example carbon taxes, on an economy which exhibits strong labor institutions, and limited finance. In this experiment two Resource tax scenarios are considered; RTax1 which results in a one-off Resource tax increase from the baseline rate of $10 \%$ to $20 \%$, and RTax+, where the Resource tax is slowly, but continuously increased such that it equals $R T a x 1$ at the 20 year mark. RTax+ keeps rising throughout the simulation period where the tax rate crosses the $50 \%$ mark (Figure 4.1 ).

Figure 4.2 shows the set of key macro indicators for this experiment. Real GDP falls below the BAU in both scenarios (Fig. 4.2a) where RTax1 results in an immediate decline while RTax+ diverges slowly from the BAU. These adjustments can be attributed to differential prices trends (Fig. 4.2c) which equalize at the 50 year mark. Wages (Fig. 4.2b) remain unchanged across the two scenarios. Figure 4.2f shows an increase in the share of government spending in GDP, driven by additional tax revenue. In $R T a x+$ it continues to rise, as opposed to RTax1 where it initially rises, and then stabilizes. Consumption (Fig. 4.2d) and Investment (Fig. 4.2e) shares in GDP fall over partly due to a lower demand from the private sector.

Emissions, on the whole, fall below the BAU scenario, where RTax+ shows the highest decline in absolute 


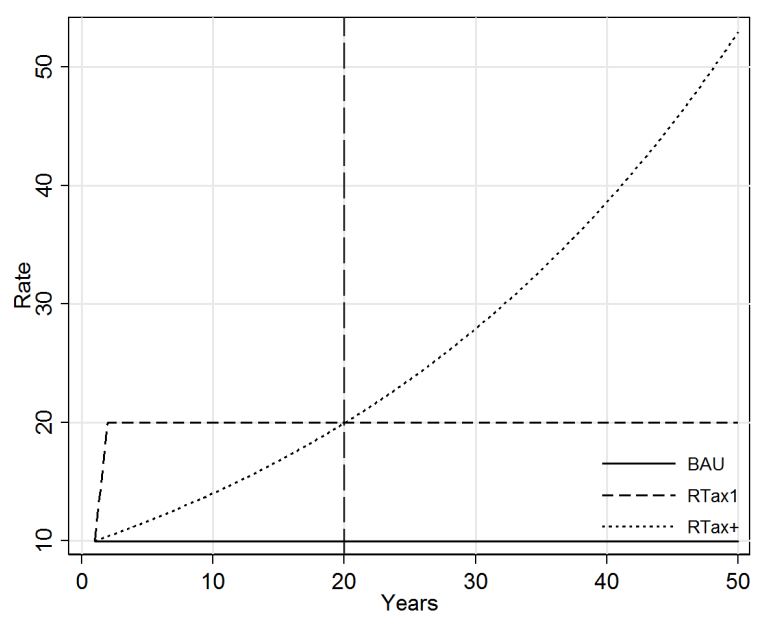

terms (Fig. 4.2g). R\&D intensity increases above the BAU level (Fig. 4.2h), partly driven by an increase in the public sector's contributions in the overall R\&D expenditure (Fig. 4.2i).

Figure 4.3 shows the adjustments across the three inputs. The direct impact of a higher Resource tax is an increase in the share of Resource costs (Fig. 4.3c). RTax1 results in a one-off spike in the share of Resource costs (Fig. 4.3c) forcing a sharp increase in R\&D allocation towards Resources (Fig. 4.3f). This causes Resource productivity to spike up (Fig. 4.3i), eventually slowing down and stabilizing to BAU trends. $R T a x+$ shows a gradual increase in the share of Resource costs. As the price of Resources continues to rise (Fig. 4.3c), R\&D investment in Resources keep rising as well (Fig. 4.3f) resulting in a continuous increase in Resource productivity, which eventually overtakes the Tax1 scenario somewhere around the 30 year mark (Fig. 4.3i).

These two tax scenarios have very different implications for Labor productivity. In RTax1, Resource costs initially dominate Labor costs reducing the R\&D allocation for Labor in a very short span. As Resource achieves its desired productivity level due to exceptionally high R\&D allocation in RTax1, the share of Labor costs starts to rise, forcing firms to shift investment back to Labor-saving technologies, such that the R\&D Labor share rises above the BAU level (Fig. 4.3d). In contrast, $R T a x+$, continuously reduces the share of Labor costs (Fig. 4.3a), allowing for a continuous increase in R\&D allocation towards Resources (Fig. 4.3f) crowding out Labor sector's R\&D investment, that creates a constant pressure to increase wages especially as the gap between current and target wage share increases over time.

To analyze the impact of redirection of Resources towards one input, we look at relatively productivity levels of the three inputs to measure for crowding-out. We calculate the input requirement for producing one unit of output to relative Labor and Resource inputs required in combination with one unit of Capital. 
Figure 4.2: Experiment 1 - Macro indicators

(a) Real GDP $(y)$

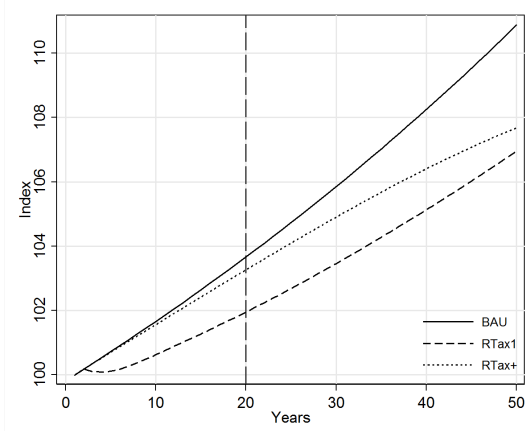

(d) Consumption share $(C / Y)$

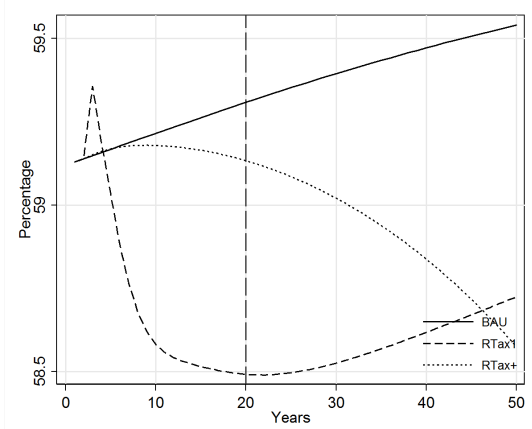

(g) Emissions (Emm)

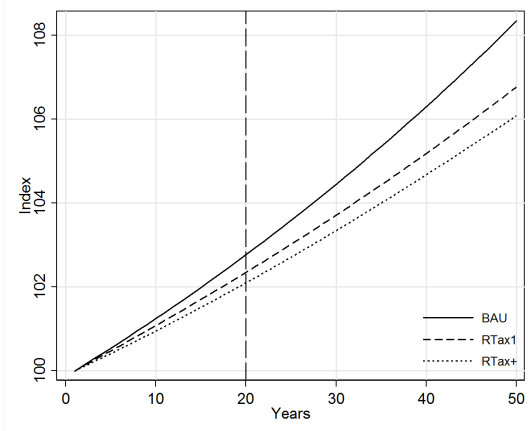

(b) Wage rate $\left(p_{t}^{L}\right)$

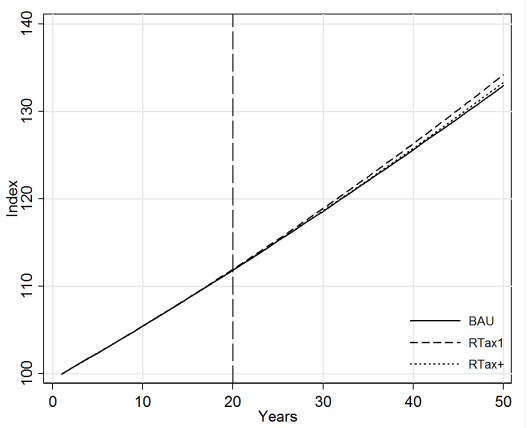

(e) Investment share $(I / Y)$

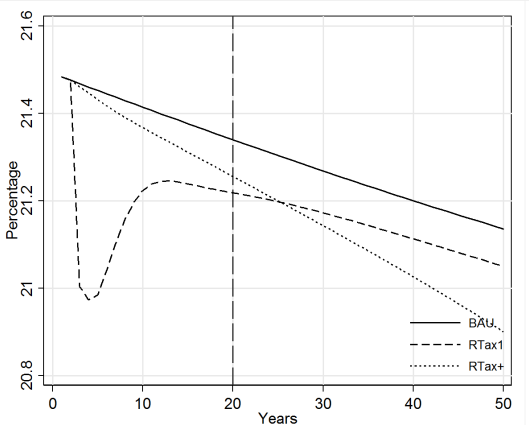

(h) R\&D Intensity $(R \& D / Y)$

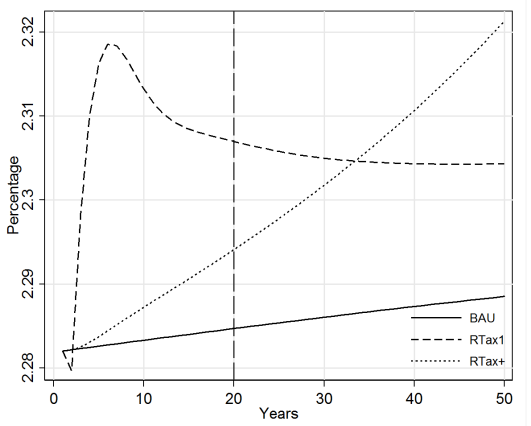

(c) Prices $(p)$

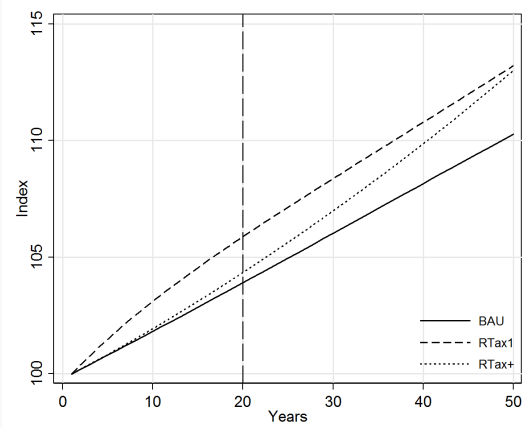

(f) Government share $(G / Y)$

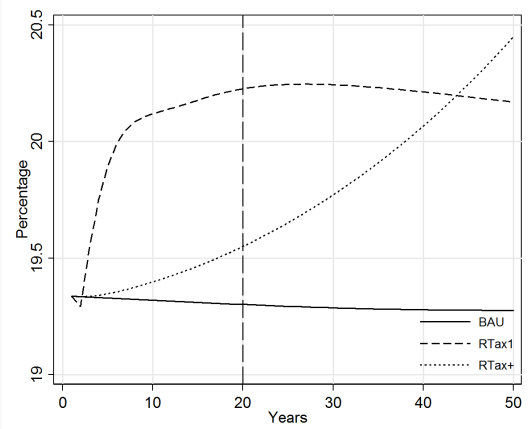

(i) Public R\&D share $\left(R \& D^{G} / R \& D\right)$

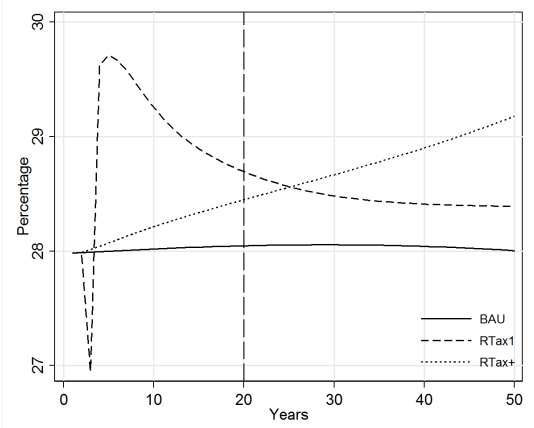


Figure 4.3: Experiment $1-\mathrm{R} \& \mathrm{D}$ and productivity

(a) Labor share in costs

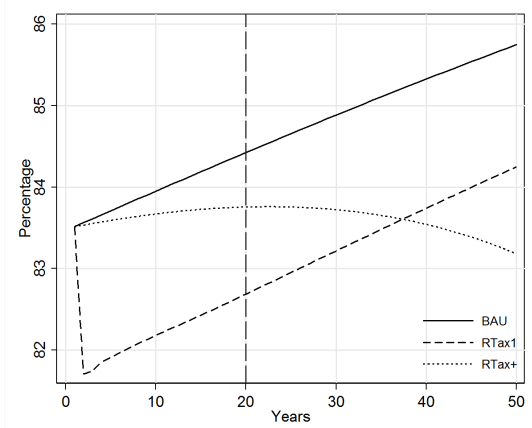

(d) Labor share in R\&D $\left(\phi^{L}\right)$

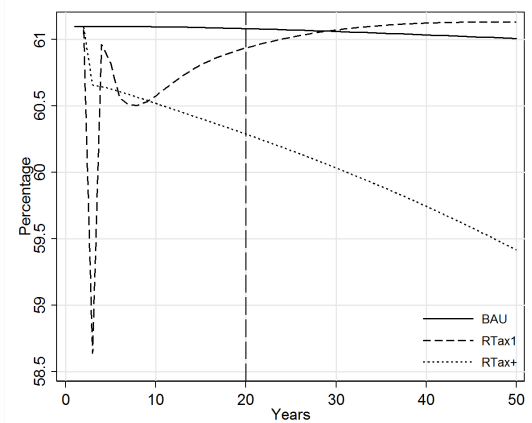

(g) Labor productivity $\left(\epsilon^{L}\right)$

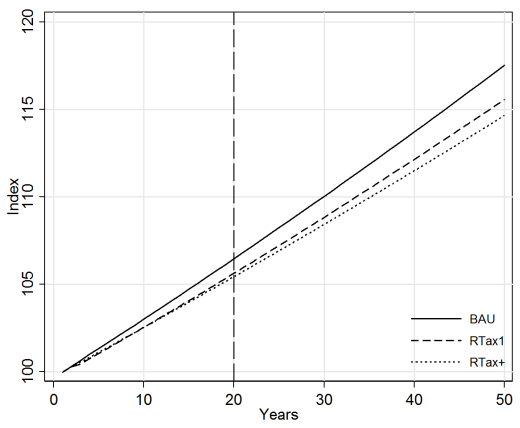

(b) Capital share in costs

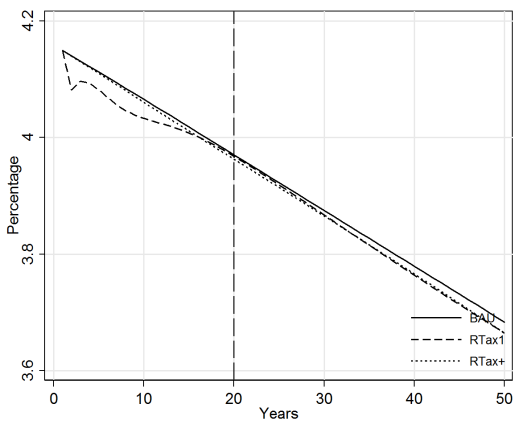

(e) Capital share in $\mathrm{R} \& \mathrm{D}\left(\phi^{K}\right)$

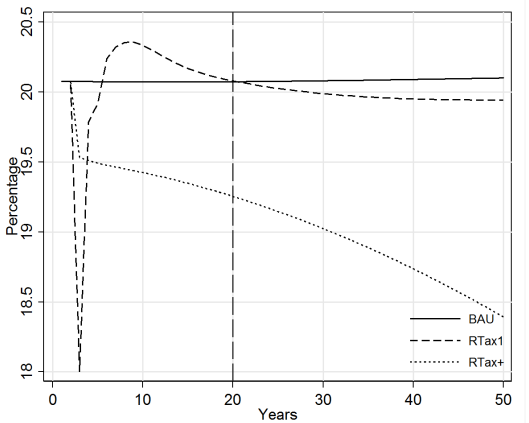

(h) Capital productivity $\left(\epsilon^{K}\right)$

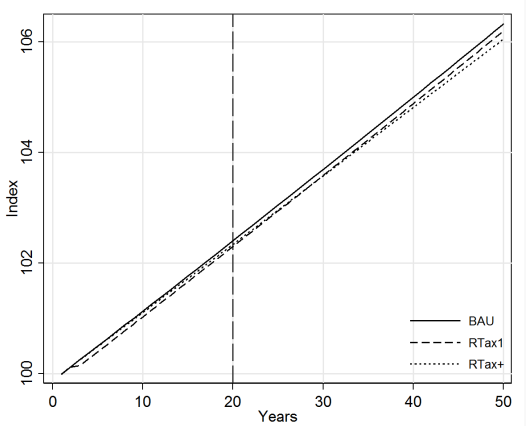

(c) Resource share in costs

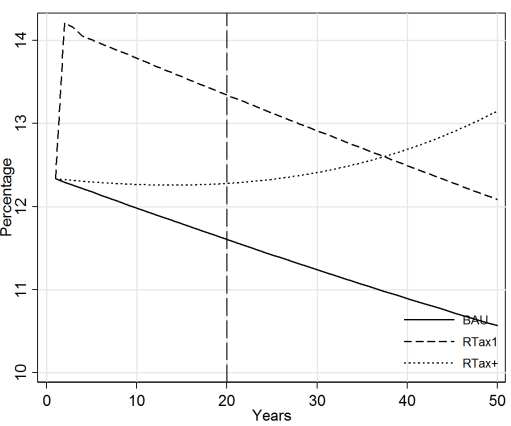

(f) Resource share in $\mathrm{R} \& \mathrm{D}\left(\phi^{R}\right)$

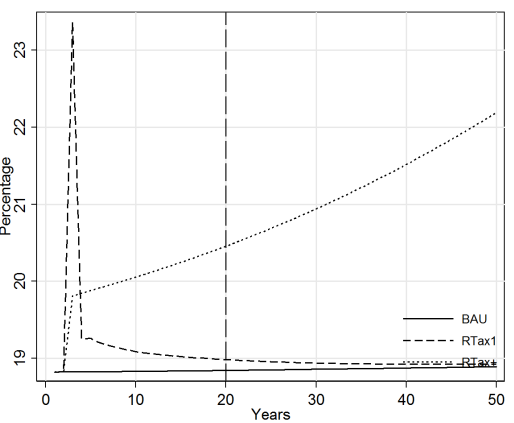

(i) Resource productivity $\left(\epsilon^{R}\right)$

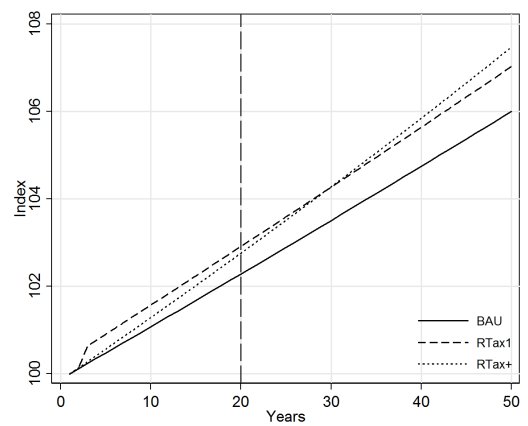


In other words, we make Capital the numéraire for all time periods. This representation allows us to explore evolution of relative productivities of the three inputs over time in a 2-D graph. The slope of the relative $\mathrm{L} / \mathrm{R}$ productivity curve can be derived as:

$$
L / R=\frac{\epsilon_{t}^{L}}{\epsilon_{t}^{K}} / \frac{\epsilon_{t}^{R}}{\epsilon_{t}^{K}}=\frac{\epsilon_{t}^{L}}{\epsilon_{t}^{R}}
$$

A steeper L/R curve implies that Labor becomes more efficient relative to Resources over time, or less of it is required to produce a unit of output. Since inputs are perfect complements, a relatively high productivity gain in one input is not desirable since it needs to be used in combination with other inputs whose costs might be rising due to a relatively slow increase in productivity. This can potentially result in a net negative effects due to rising costs (Acemoglu et al., 2012; Lamperti et al., 2016). Therefore a flatter curve, which implies relatively homogenous co-evolution of Labor and Resource productivities, is preferred over a steeper one.

For Experiment 1, the L/R curve is shown in Figure 4.4 for the two tax scenarios. RTax1 gives a short boost to Labor productivity moving it downwards eventually stabilizing to roughly the same gradient as the BAU, implying that investment in Labor still dominates the R\&D investment. In contrast, in RTax+, the L/R curve becomes flatter, showing constant innovation in Resources that permanently crowd out the Labor productivity gains shifting to a relatively higher Resource-saving technology regime through constant intervention. This also results in a slower rise in costs relative to the RTax1 scenario, allowing the economy to adapt to slowly evolving cost structures.

Figure 4.4: Experiment 1 - Technological development of inputs

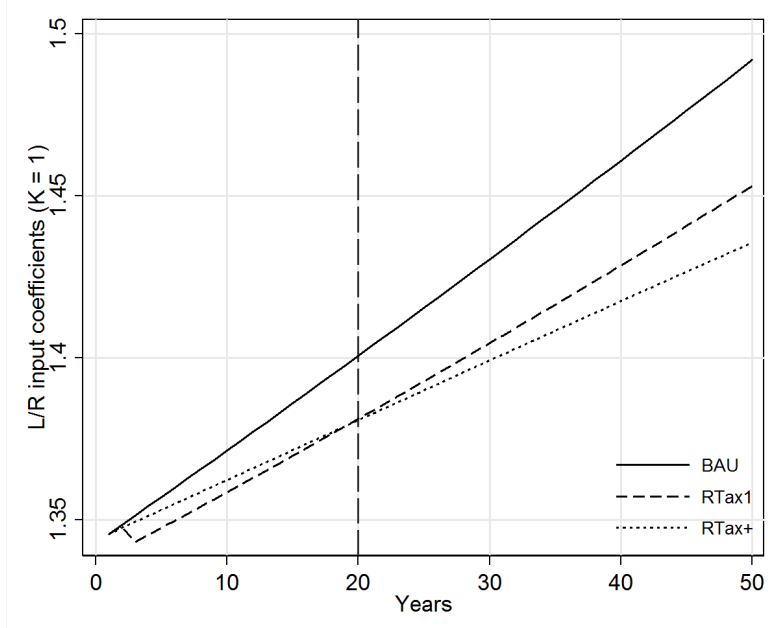

This experiment highlights a crucial policy outcome of this paper: in an economy with induced technological change, a continuously rising Resource or "carbon" tax will be more effective in the long run 
in reducing emissions than a one-off tax increase. While RTax1 manages to improve productivity in the short-run, rising wage costs eventually dominate the firm's decision making process. Hence a constantly increasing Resource tax is needed to direct technological change away from Labor-saving technologies.

Qualitatively, this result is different from Acemoglu et al. (2012), which suggests that if the inputs are complements, then the only way to prevent an environmental disaster is to stop long-run growth. Lamperti et al. (2016) builds on the Acemoglu et al. (2012) framework, and suggests that shutting off long-growth is not necessary, but timing matters. If inputs are complements (or even weak substitutes), a commandand-control policy can an environmental disaster without stopping long-run growth. While we agree with the conclusions of Lamperti et al. (2016), our model highlights that market-conform instruments like taxes can still be useful provided they are continuously increased (in order to direct technological change) rather than aimed at an optimal level. For example, if the gap between actual and desired resource productivity increases, then a faster resource tax rate growth can help close this gap. While a continuously increasing tax can have a dampening effect on household demand growth, carefully managed government spending can still boost consumption and investment putting the economy back on a growth trajectory.

\subsection{Experiment 2-Green public RED}

In the second experiment, the impact of a centralized "green" policies (or command-and-control polices) are explored. The government influences Resource productivity directly by autonomously increasing the share of public R\&D towards Resources. In the BAU, the government allocates its $R \& D$ budget to each of the three inputs equally such that $\lambda_{1 G}=\lambda_{2 G}=\lambda_{3 G}=0.33$. Two scenarios are introduced here; $R \mathscr{E} D+$, where the public R\&D allocation towards Resource is increased to $\lambda_{3 G}=0.80$. The remaining budget is split evenly across the other two inputs such that $\lambda_{1 G}=\lambda_{2 G}=0.10$. The aim of this scenario is to look at direct policy interventions by the government through internal redistribution of public R\&D budgets. In the second scenario, $R \xi D+$ is combined with $R T a x+$ from Experiment 1, to test the implications of hybrid policies on the economy.

Macro outcomes are summarized in Figure 4.5. The overall impact on the real GDP (Fig. 4.5a) and wages (Fig. $4.5 \mathrm{~b})$ is negligible in the $R \mathscr{E} D+$ scenario, while in the hybrid $(R \mathscr{E} D+R T a x+)$ scenario, real GDP falls below the BAU. This is because public R\&D policy only changes the composition of government spending, but not its level relative to government's income that is generated through tax revenue. Prices rise above the BAU level in both scenarios showing a higher increase in the hybrid policy (Fig. 4.5c). In $R \mathscr{E} D+$, consumption share stays stable (Fig. 4.5d), while government share falls slightly (Fig. 4.5f) and investment shares rise (4.5e). The reverse happens in the hybrid policy, where due to rising taxes, government income increases, resulting in higher spending.

Emissions fall in both scenarios where the hybrid policy shows a higher decline (Fig. 4.5g). R\&D intensity falls slightly below BAU in $R E D+$ but rises significantly in the hybrid policy (Fig. $4.5 \mathrm{~h}$ ) driven 
both by lags in spending adjustments (Fig. 4.5h) and rising government spending (Fig. 4.5i). The share of public R\&D increases in both scenarios (Fig. 4.5i).

Figure 4.5: Experiment 2-Macro indicators

(a) Real GDP $(y)$

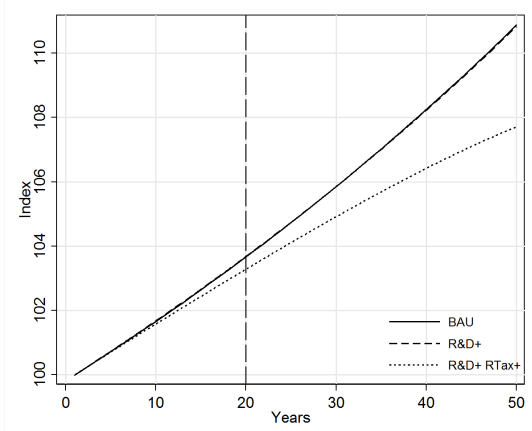

(d) Consumption share $(C / Y)$

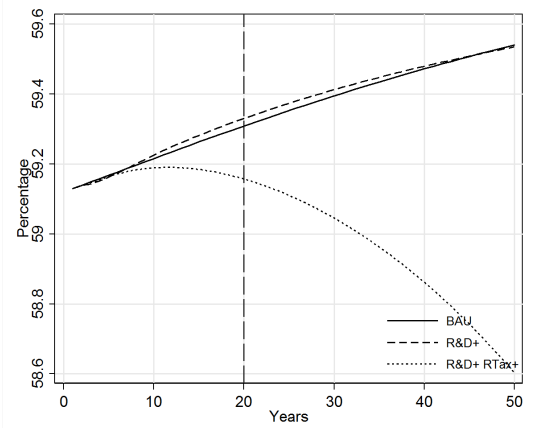

(g) Emissions $(E m m)$

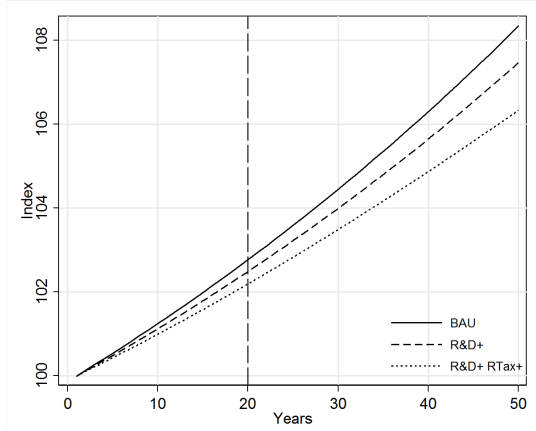

(b) Wage rate $\left(p_{t}^{L}\right)$

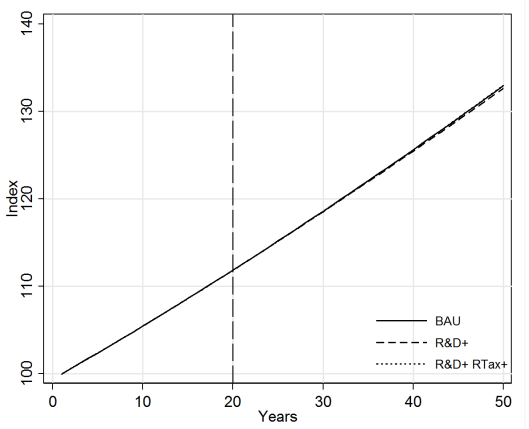

(e) Investment share $(I / Y)$

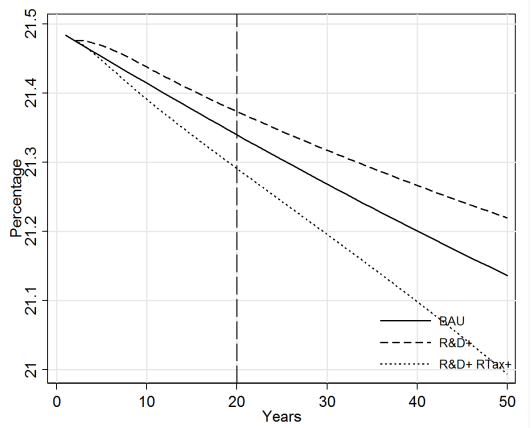

(h) R\&D Intensity $(R \& D / Y)$

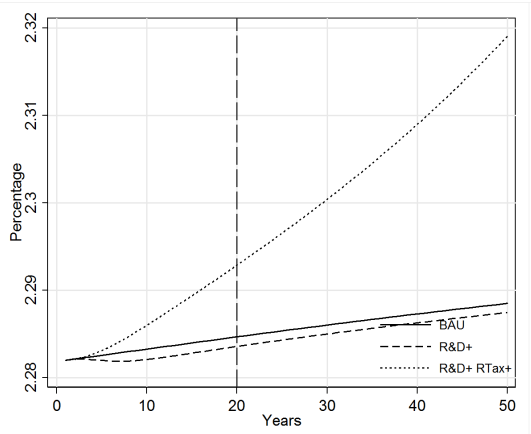

(c) Prices $(p)$

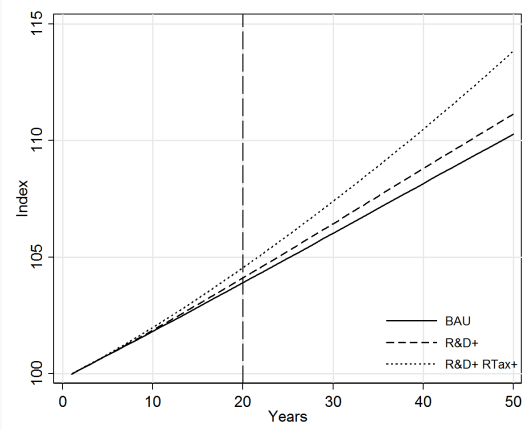

(f) Government share $(G / Y)$

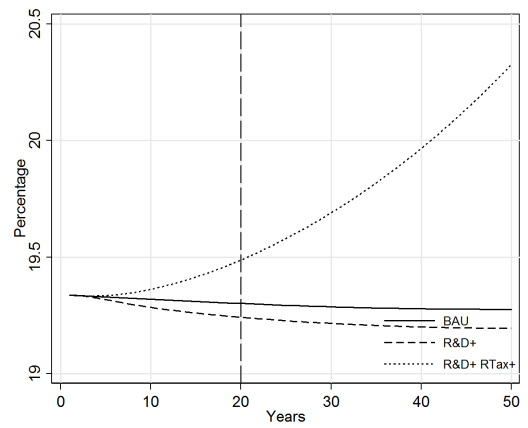

(i) Public R\&D share $\left(R \& D^{G} / R \& D\right)$

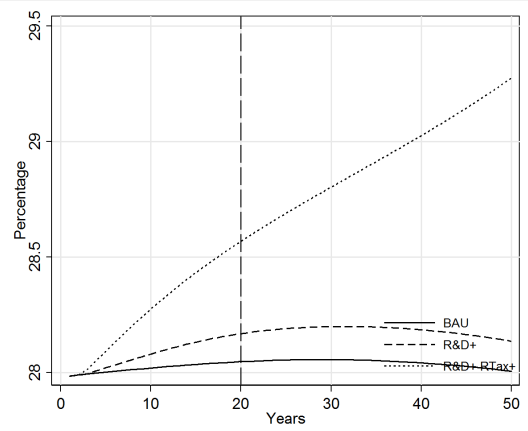

Figure 4.6 shows the impact on individual inputs of the two scenarios which have very different implications on the input costs. While in $R \& D+$, the government permanently shifts the R\&D allocation towards Resources (Fig. 4.6f), resulting in higher-than-BAU productivity gains (Fig. 4.6i), the Resource share in costs declines (Fig. 4.6c). The autonomous shift towards Resources results in lower allocation of R\&D 
towards Labor (Fig. 4.6d), resulting in lower-than-BAU productivity gains (Fig. 4.6g), and an increase in the share of costs (Fig. 4.6a). As a consequence, prices rise above BAU levels in the $R \& D+$ scenario (Fig. $4.5 \mathrm{c})$.

Alternatively the hybrid scenario $R \& D+R T a x+$, introduces the additional continuously rising tax which continuously increase the Resource share in costs (Fig. 4.6c). This pushes R\&D allocation towards Resources even more (Fig. 4.6f), continuously redirecting R\&D investment away from Labor (Fig. 4.6d), whose share in costs also continues to decline (Fig. 4.6a). As a consequence, in the hybrid scenario, Resources exhibit the highest productivity gains, and Labor the lowest.

Overall, the net effect is small since a decline in household consumption (Fig. 4.5d) is compensated by higher government spending (Fig. 4.5f). This implies that, by directing public R\&D spending towards Resources, the net effect can still result in a slight slowdown of the economic growth while improving the overall Resource productivity (Fig. 4.6i) resulting in lower emissions (Fig. 4.5g).

Figure 4.7 shows the development of input ratios. In both scenarios, the $\mathrm{L} / \mathrm{R}$ curve becomes flatter, implying that Resource productivity relative to Labor productivity increases at a faster rate than the BAU. The hybrid policy shows the flattest curve highlighting that, Resource productivity gains catch up with Labor productivity.

This experiment illustrates how an exogenous allocation of "green" public R\&D can enable a substitution away from a Labor-saving investment towards a Resource-saving investment. In our model it does so with a small impact on the overall growth in the economy while also reducing emission levels. In this case the state is solely responsible for green investment. The government is also responsible for ensuring the demand remains high by increasing it expenditure share in the economy. This is still achievable with a pro-cyclical policy but with high lags in spending adjustments. This hybrid policy strategy is more effective in terms of Resource efficiency gains where the mix of market-based and command-and-control-based policies can enable high Resource efficiency gains while also ensuring demand-creation in the process to keep the economy on a reasonable growth path.

\section{Conclusions}

After the 2008 financial crisis, a key challenge has been to overcome the deep recession while also tackling climate change by reducing non-renewable Resource use and emissions (EC 2016a). A recent strategy proposed to address this problem is increased $\mathrm{R} \& \mathrm{D}$ spending supported both by private and public sectors (OECD 2015). Firms invest in innovation to save costs, improve efficiency, increase competitiveness and increase profit margins. The government wants to maximize social welfare by minimizing environmental externalities (Popp et al. 2010). Mainstream endogenous growth theory discusses processes through which technological change can be directed towards greener resources. While this literature has contributed sig- 
Figure 4.6: Experiment 2-R\&D and productivity

(a) Labor share in costs

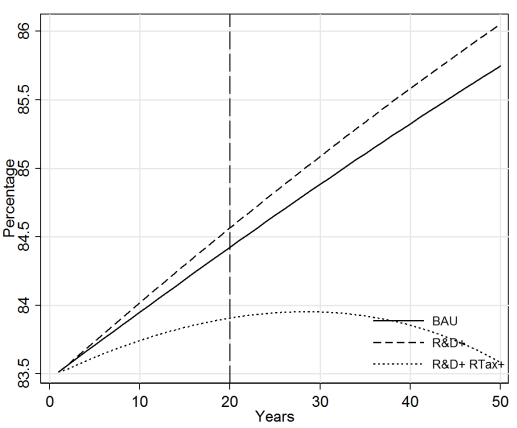

(d) Labor share in R\&D $\left(\phi^{L}\right)$

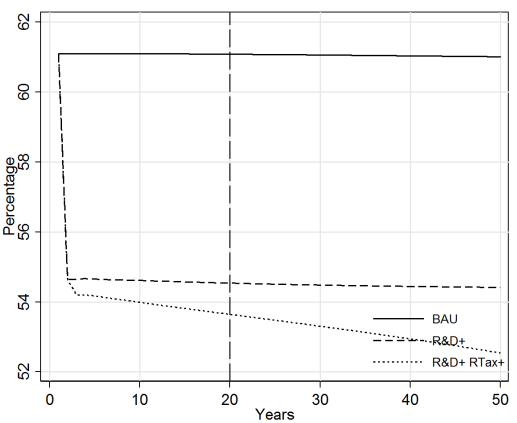

(g) Labor productivity $\left(\epsilon^{L}\right)$

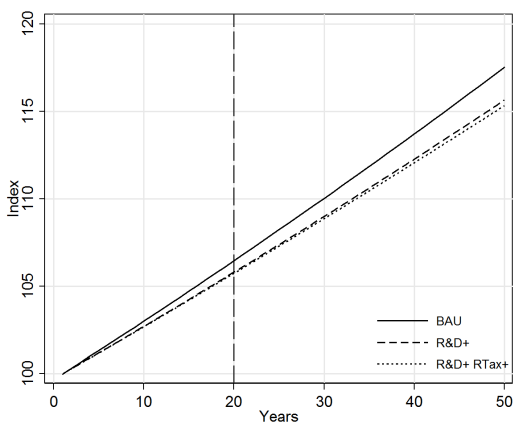

(b) Capital share in costs

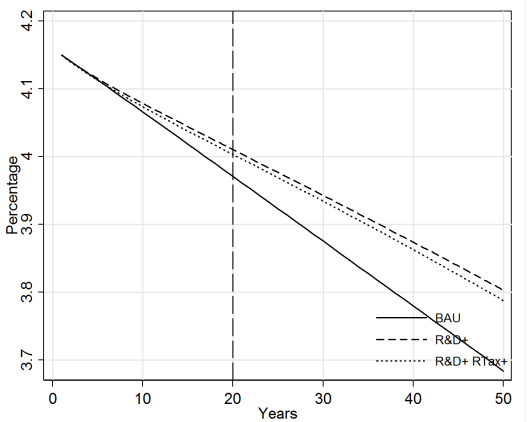

(e) Capital share in $\mathrm{R} \& \mathrm{D}\left(\phi^{K}\right)$

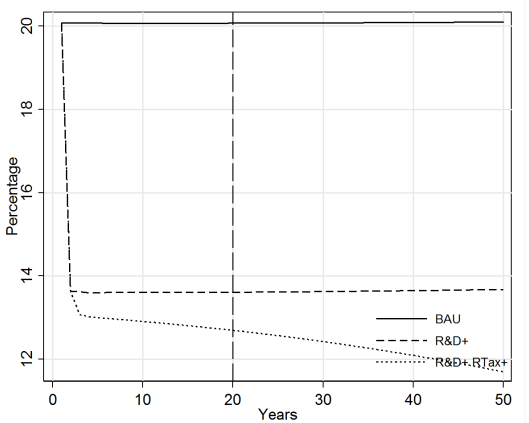

(h) Capital productivity $\left(\epsilon^{K}\right)$

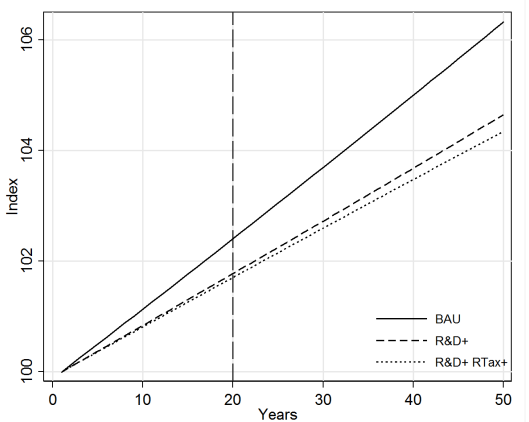

(c) Resource share in costs

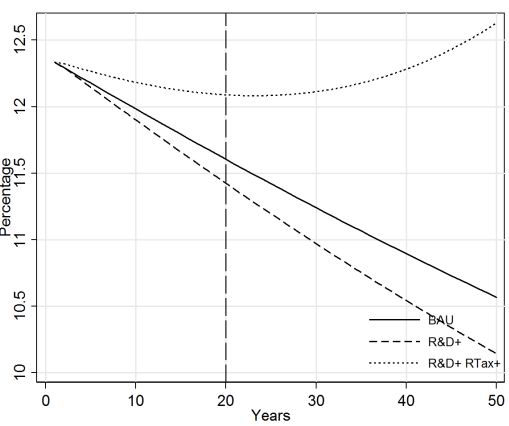

(f) Resource share in $\mathrm{R} \& \mathrm{D}\left(\phi^{R}\right)$

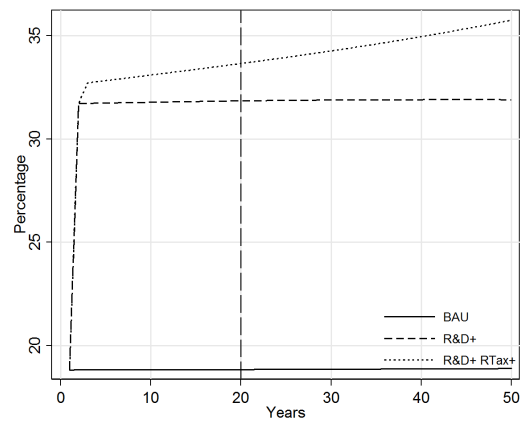

(i) Resource productivity $\left(\epsilon^{R}\right)$

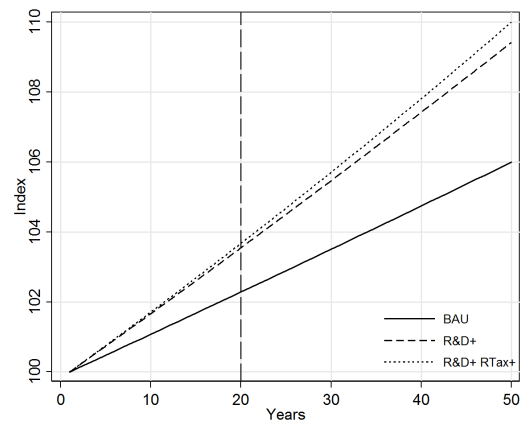


Figure 4.7: Experiment 2- Technological development of inputs

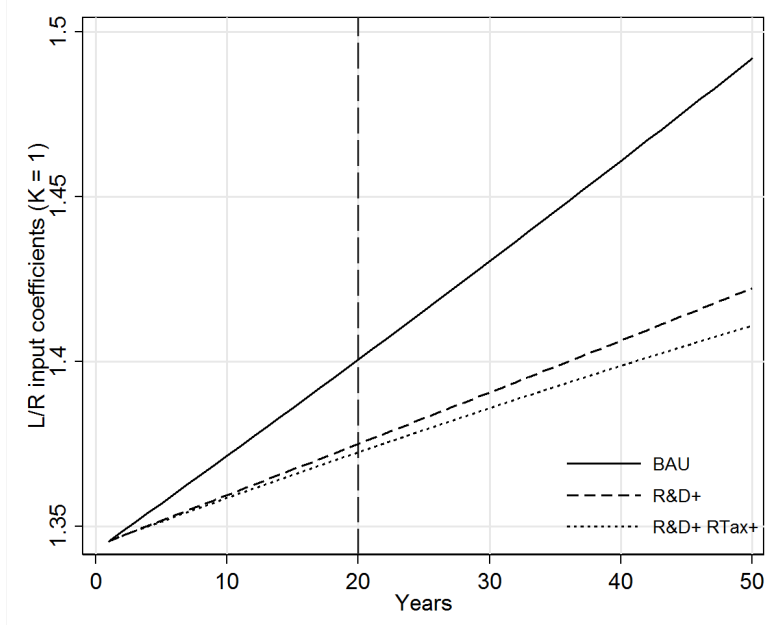

nificantly to the understanding of the mechanisms through which the climate policies can be understood, three aspects still need to be addressed in literature. First, institutional structures pull their weight on how the resources are invested affecting how the economy evolves. For example, labor institutions push for higher wages, directing investment towards labor-saving technologies. Second, the discussion on the role of finance in R\&D investment decisions is missing. Firms invest in R\&D based on profitability. Similarly, the government R\&D expenditure is determined by pro-cyclical policies. Hence R\&D investment is not only budget constrained but is also dependent on the overall economic performance.

This paper has presented a post-Keynesian ecological macroeconomic model with endogenous technological change. It incorporates the induced innovation framework in a demand-driven multi-sector stock-flow consistent (SFC) model. A key advantage of the SFC framework is its ability to financial flows across sectors and thus allows us to better assess the feedback effects of climate policies on the overall economy. Within this framework, we propose an innovative way of modeling R\&D decision across competing yet complementary inputs. We suggest that R\&D investment decisions can be understood as a portfolio choice which responds to relative changes in input costs. If social wage norms index wage growth to labor productivity growth, technological progress will be primarily labor-saving.

The paper explores policy scenarios, which can enable a transition towards resource-saving technologies. Two climate policy experiments are conducted. The first experiment compares a one-off market-based resource (or carbon) tax increase with a continuous resource tax increase. This experiment shows that in world of endogenous technological change with demand-led growth, an active public sector, and labormarket hysteresis, a continuously increasing resource tax is necessary to shift technological process to increase resource productivity. The resource tax policy involves rising government shares, thus public spending policy 
is important to avoid shortfalls in the aggregate demand. In the second experiment, a centralized green policy is explored where the government autonomously shifts the public R\&D's budget towards Resources. This is then combines it with a continuously rising Resource tax from the first experiment. As we assume sluggish adjustment of government expenditures to rising tax income the impact of this hybrid market- and command-and-control-based policy is a growth trajectory that is slightly below BAU, but is most effective in transitioning out of the labor-saving technologies to resource-saving technologies.

This paper contributes to recently emerging post-Keynesian ecological macroeconomic literature where the role of $\mathrm{R} \& \mathrm{D}$ expenditure, and directed technological change is incorporated in a multi-sector model with fully tracked financial flows. While most of mainstream environmental economics perceives of environmental taxes and subsidies as a static attempt to internalize the external effects of emissions, and then let markets do the adjustment, our approach regards the resource tax as a dynamic instrument that is used to direct technological innovation over a longer time horizon. Our findings are in contrast to Acemoglu et al. (2012), who argue that if inputs are complements then the only way to prevent an environmental disaster is to prevent long-run growth. Additionally we agree with the conclusions of Lamperti et al. (2016), which suggest that well-timed command-and-control policies are likely to be more effective than market-based policies. We extend this to suggest that market-based instruments can still work provided they are continuously increased to help close the technological progress gap created through path-dependencies to enable a green transition. The model also highlights that the interactions across and within different economic agents (Households, Firms, Banks, and the Government) combined with an active public sector (Mazzucato 2015, 2016) and financial constraints, cannot be excluded from climate policy analysis.

While the macro model presented in this paper is highly stylized, this framework naturally allows extension in several directions. This ranges from introducing a more complex financial system with credit rationing and financial instability (Monasterolo and Raberto 2018; Caiani et al. 2018) including an independent central bank that can conduct green monetary and fiscal polcies. A richer climate box can also be introduced with integrated material, energy, and emission flows (Berg et al. 2015; Dafermos et al. 2017; Lamperti et al. 2017). Future research can take two steps to make non-mainstream climate models more comparable with mainstream ones. First, expanding the firm sector to explicitly include substitutable "green" and "brown" sectors which allows us to incorporate lock-in effects of sector-specific investments, giving a richer picture of path-dependency in policy analysis. Second, incorporating a production function that allows for weak or strong substitution across inputs (for example, by utilizing the generic constant elasticity of substitution (CES) production functions) (Acemoglu et al. 2012; Lamperti et al. 2016; Tavani and Zamparelli 2017). Such a model would abandon the Kaleckian notion of variable capacity utilization, but would allow to test for the impact of various climate policies on the productivity trajectories resulting from different policy scenarios (Balint et al. 2017). These extensions can be extended and calibrated using large-scale SFC-ABM models where environmental policies can be simulated in a holistic multi-sectoral environment-economy framework. 


\section{Bibliography}

Rob Aalbers, Victoria Shestalova, and Viktória Kocsis. Innovation policy for directing technical change in the power sector. Energy Policy, 63:1240-1250, dec 2013. ISSN 03014215. doi: 10.1016/j.enpol.2013.09.013. URL http://linkinghub. elsevier.com/retrieve/pii/S0301421513009373.

Daron Acemoglu. Why Do New Technologies Complement Skills? Directed Technical Change and Wage Inequality. The Quarterly Journal of Economics, 113(4):1055-1089, nov 1998. ISSN 0033-5533. doi: 10.1162/003355398555838. URL http://qje.oxfordjournals.org/cgi/doi/10.1162/003355398555838.

Daron Acemoglu. Directed Technical Change. The Review of Economic Studies, 69(4):781-809, 2002. ISSN 00346527. doi: $10.2307 / 1556722$.

Daron Acemoglu, Philippe Aghion, Leonardo Bursztyn, and David Hemous. The Environment and Directed Technical Change. American Economic Review, 102(1):131-166, feb 2012. ISSN 0002-8282. doi: 10.1257/aer.102.1.131. URL http://pubs. aeaweb.org/doi/10.1257/aer.102.1.131.

Daron Acemoglu, Ufuk Akcigit, Douglas Hanley, and William Kerr. Transition to Clean Technology. Journal of Political Economy, 124(1):52-104, feb 2016. ISSN 0022-3808. doi: 10.1086/684511. URL http://www.journals.uchicago.edu/doi/ $10.1086 / 684511$.

Philippe Aghion, Philippe Askenazy, Nicolas Berman, Gilbert Cette, and Laurent Eymard. Credit constraints and the cyclicality of R\&D investment: Evidence from France. Journal of the European Economic Association, 10(5):1001-1024, 2012. ISSN 15424766. doi: 10.1111/j.1542-4774.2012.01093.x.

Philippe Aghion, David Hemous, Ralf Martin, John Van Reenen, Antoine Dechezleprêtre, David Hémous, Ralf Martin, and John Van Reenen. Carbon Taxes, Path Dependency, and Directed Technical Change: Evidence from the Auto Industry. Journal of Political Economy, 124(1):1-51, feb 2016. ISSN 0022-3808. doi: 10.1086/684581. URL http://www.journals. uchicago.edu/doi/10.1086/684581.

W Brian Arthur. Complexity and the Economy. In Horst Hanusch, editor, Elgar companion to neo-Schumpeterian economics, volume 248, pages 1102-1111. Cheltenham, 1999.

David B. Audretsch. Firm profitability, growth, and innovation. Review of Industrial Organization, 10(5):579-588, oct 1995. ISSN 0889-938X. doi: 10.1007/BF01026883. URL http://link.springer.com/10.1007/BF01026883.

Robert Axtell. Why agents? On the varied motivations for agent computing in the social sciences. 2000.

Robert Axtell. Economics as Distributed Computation. In Hiroshi Deguchi, Keiki Takadama, and Takao Terano, editors, Meeting the Challenge of Social Problems via Agent-Based Simulation, chapter Economics, pages 3-23. Springer, Tokyo, Japan, 2003.

T. Balint, F. Lamperti, A. Mandel, M. Napoletano, A. Roventini, and A. Sapio. Complexity and the Economics of Climate Change: A Survey and a Look Forward. Ecological Economics, 138:252-265, aug 2017. ISSN 09218009. doi: 10.1016/j. ecolecon.2017.03.032. URL http://dx.doi.org/10.1016/j.ecolecon.2017.03.032.

Stefano Battiston, Michelangelo Puliga, Rahul Kaushik, Paolo Tasca, and Guido Caldarelli. DebtRank: Too Central to Fail? Financial Networks, the FED and Systemic Risk. Scientific Reports, 2(1):541, dec 2012. ISSN 2045-2322. doi: 10.1038/srep00541. URL http://www.nature.com/articles/srep00541.

Alberto Behar. Directed technical change, the elasticity of substitution and wage inequality in developing countries. 2009.

Matthew Berg, Brian Hartley, and Oliver Richters. A stock-flow consistent inputoutput model with applications to energy price shocks, interest rates, and heat emissions. New Journal of Physics, 17(1):015011, jan 2015. ISSN 1367-2630. doi: 10.1088/1367-2630/17/1/015011.

Amit Bhaduri. Endogenous economic growth: A new approach. Cambridge Journal of Economics, 30(1):69-83, 2006. ISSN 0309166X. doi: 10.1093/cje/bei047. 
Hans P. Binswanger and Vernon W. Ruttan. Induced Innovation: Technology, Institutions, and Development. Johns Hopkins University Press, 1978.

Mathias Binswanger. Technological progress and sustainable development: what about the rebound effect? Ecological Economics, 36(1):119-132, 2001. ISSN 0921-8009. doi: http://dx.doi.org/10.1016/S0921-8009(00)00214-7. URL http://www.sciencedirect.com/science/article/pii/S0921800900002147.

Valentina Bosetti, Carlo Carraro, Marzio Galeotti, Emanuele Massetti, and Massimo Tavoni. WITCH - A World Induced Technical Change Hybrid Model. Energy Journal, 27(May):13-37, 2006. ISSN 1556-5068. doi: 10.2139/ssrn.948382. URL http: //www.ssrn. com/abstract=948382.

Valentina Bosetti, Emanuele Massetti, and Massimo Tavoni. The WITCH Model. Structure, Baseline, Solutions. 2007. URL http: //www.ssrn. com/abstract $=960746$

A. Lans Bovenberg and Sjak A. Smulders. Transitional Impacts of Environmental Policy in an Endogenous Growth Model. International Economic Review, 37(4):861, nov 1996. ISSN 00206598. doi: 10.2307/2527315. URL https://www.jstor. org/stable/2527315?origin=crossref.

Lucas Bretschger. Economics of technological change and the natural environment: How effective are innovations as a remedy for resource scarcity? Ecological Economics, 54(2-3):148-163, 2005. ISSN 09218009. doi: 10.1016/j.ecolecon.2004.12.026.

Alessandro Caiani, Antoine Godin, Eugenio Caverzasi, Mauro Gallegati, Stephen Kinsella, and Joseph E. Stiglitz. Agent based-stock flow consistent macroeconomics: Towards a benchmark model. Journal of Economic Dynamics and Control, 69:375-408, 2016. ISSN 01651889. doi: 10.1016/j.jedc.2016.06.001. URL http://dx.doi.org/10.1016/j.jedc.2016.06.001. Alessandro Caiani, Ermanno Catullo, and Mauro Gallegati. The effects of fiscal targets in a monetary union: a Multi-Country Agent-Based Stock Flow Consistent model. Industrial and Corporate Change, (612955):1-38, apr 2018. ISSN 0960-6491. doi: 10.1093/icc/dty016. URL https://academic.oup.com/icc/advance-article/doi/10.1093/icc/dty016/4964718.

Samuel Carrara and Giacomo Marangoni. Including system integration of variable renewable energies in a constant elasticity of substitution framework: The case of the WITCH model. Energy Economics, 64:612-626, 2017. ISSN 01409883. doi: 10.1016/j.eneco.2016.08.017. URL http://dx.doi.org/10.1016/j.eneco.2016.08.017.

Carlo Carraro, Reyer Gerlagh, and Bob van der Zwaan. Endogenous technical change in environmental macroeconomics. Resource and Energy Economics, 25(1):1-10, 2003. ISSN 09287655. doi: 10.1016/S0928-7655(02)00016-7.

M. S. Cato. Green economics: putting the planet and politics back into economics. Cambridge Journal of Economics, 36(5): 1033-1049, 2012. ISSN 0309-166X. doi: 10.1093/cje/bes022. URL http://cje.oxfordjournals.org/cgi/doi/10.1093/cje/ bes022.

Eugenio Caverzasi and Antoine Godin. Post-Keynesian stock-flow-consistent modelling: a survey. Cambridge Journal of Economics, 39(1):157-187, jan 2015. ISSN 0309-166X. doi: 10.1093/cje/beu021. URL https://academic.oup.com/cje/ article-lookup/doi/10.1093/cje/beu021.

Jacob Cohen. Copeland's Moneyflows after Twenty-Five Years: A Survey. Journal of Economic Literature, 10(1):1-25, 1972. ISSN 00220515. URL http://www.jstor.org/stable/2720888.

Morris A Copeland. Social Accounting for Moneyflows. The Accounting Review, 24(3):254-264, 1949.

Yannis Dafermos, Maria Nikolaidi, and Giorgos Galanis. A stock-flow-fund ecological macroeconomic model. Ecological Economics, 131:191-207, jan 2017. ISSN 09218009. doi: 10.1016/j.ecolecon.2016.08.013. URL http://dx.doi.org/10.1016/ j.ecolecon.2016.08.013.

Herman E. Daly. Towards an environmental macroeconomics. Land Economics, 67(2):255-259, 1991. ISSN 1097-6868. doi: 10.1016/j.ajog.2012.11.038.

Claudio H. dos Santos and Gennaro Zezza. a Simplified, Benchmark', Stock-Flow Consistent Post-Keynesian Growth Model. Metroeconomica, 59(3):441-478, 2008. ISSN 0026-1386. doi: 10.1111/j.1467-999X.2008.00316.x. URL http://doi.wiley . com/10.1111/j.1467-999X.2008.00316.x. 
Giovanni Dosi. Sources, Procedures, and Microeconomic Effects of Innovation. Journal of Economic Literature, 26(3):11201171, 1988. ISSN 00220515. doi: 10.2307/2726526.

Giovanni Dosi, Giorgio Fagiolo, and Andrea Roventini. Schumpeter meeting Keynes: A policy-friendly model of endogenous growth and business cycles. Journal of Economic Dynamics and Control, 34(9):1748-1767, 2010. ISSN 01651889. doi: 10.1016/j.jedc.2010.06.018. URL http://www.sciencedirect.com/science/article/pii/S016518891000148X.

Giovanni Dosi, Giorgio Fagiolo, Mauro Napoletano, and Andrea Roventini. Income distribution, credit and fiscal policies in an agent-based Keynesian model. Journal of Economic Dynamics and Control, 37(8):1598-1625, 2013. ISSN 01651889. doi: 10.1016/j.jedc.2012.11.008. URL http://www.sciencedirect.com/science/article/pii/S0165188913000213.

Nepomuk Dunz and Asjad Naqvi. Environmental and Labor Policies in a North-South SFC Model. 2017.

Amitava Krishna Dutt. Aggregate Demand, Aggregate Supply and Economic Growth. International Review of Applied Economics, 20(3):319-336, 2006. ISSN 0269-2171. doi: 10.1080/02692170600736094.

Antonio Carlos Macedo e Silva and Claudio H. dos Santos. Peering over the edge of the short period? The Keynesian roots of stock-flow consistent macroeconomic models. Cambridge Journal of Economics, 35(1):105-124, 2011. ISSN 0309-166X. doi: 10.1093/cje/bep083. URL https://academic.oup.com/cje/article-lookup/doi/10.1093/cje/bep083.

EC. EU2020: A strategy for smart, sustainable and inclusive growth. Technical Report 1, European Commission, 2010.

EC. The Road from Paris: assessing the implications of the Paris Agreement and accompanying the proposal for a Council decision on the signing, on behalf of the European Union, of the Paris agreement adopted under the United Nations Framework Convention on Cl. Technical report, European Commission, Brussels, 2016a. URL http://eur-lex.europa.eu/ legal-content/EN/TXT/PDF/?uri=CELEX : 52016DC0110\{\&\}from=EN.

EC. Research and innovation. Technical report, European Comission Policy Papers, 2016b. URL europa.eu/pol/rd/ index $\{$ \} $\}$ en.htm.

EC. Secular stagnation and the euro area. Technical Report Briefing February 2016, European Parliament, 2016c.

EC. Smarter, Greener, More Inclusive? Technical report, European Commission, 2017.

EIB. Climate Strategy: Mobilising finance for the transition to a low-carbon and climate-resilient economy. Technical report, European Investment Bank, 2015. URL http://www.eib.org/infocentre/publications/all/eib-climate-strategy.htm. Jiyong Eom, Jae Edmonds, Volker Krey, Nils Johnson, Thomas Longden, Gunnar Luderer, Keywan Riahi, and Detlef P. Van Vuuren. The impact of near-term climate policy choices on technology and emission transition pathways. Technological Forecasting and Social Change, 90(PA):73-88, jan 2015. ISSN 00401625. doi: 10.1016/j.techfore.2013.09.017. URL http: //linkinghub.elsevier.com/retrieve/pii/S0040162513002540.

J Doyne Farmer and Duncan Foley. The economy needs agent-based modelling. Nature, 460(August):685-686, 2009. ISSN 0028-0836. doi: 10.1038/460685a.

J. Doyne Farmer, Cameron Hepburn, Penny Mealy, and Alexander Teytelboym. A Third Wave in the Economics of Climate Change. Environmental and Resource Economics, 62(2):329-357, 2015. ISSN 15731502. doi: 10.1007/s10640-015-9965-2.

Francesco Ferrante. Induced technical change, adjustment costs and environmental policy modelling. Applied Economics, 30 (5):649-665, 1998. ISSN 0003-6846. doi: 10.1080/000368498325642. URL http://dx.doi.org/10.1080/000368498325642.

Duncan Foley and Thomas Michl. Growth and Distribution. Harvard University Press, 1999.

Giuseppe Fontana and Malcolm Sawyer. Post-Keynesian and Kaleckian thoughts on ecological macroeconomics. European Journal of Economics and Economic Policies: Intervention, 10(2):256-267, 2013. ISSN 20527764. doi: 10.4337/ejeep.2013. 02.09. URL http://ideas.repec.org/a/elg/ejeepi/v10y2013i2p256-267.html.

Giuseppe Fontana and Malcolm Sawyer. Towards post-Keynesian ecological macroeconomics. Ecological Economics, 121:186195, jan 2016. ISSN 09218009. doi: 10.1016/j.ecolecon.2015.03.017. URL http://dx.doi.org/10.1016/j.ecolecon.2015. 03.017.

M.D. Gerst, P. Wang, A. Roventini, G. Fagiolo, G. Dosi, R.B. Howarth, and M.E. Borsuk. Agent-based modeling of climate 
policy: An introduction to the ENGAGE multi-level model framework. Environmental Modelling Es Software, 44:62-75, jun 2013. ISSN 13648152. doi: 10.1016/j.envsoft.2012.09.002. URL http://linkinghub.elsevier.com/retrieve/pii/ S1364815212002332.

Nigel Gilbert. Agent-Based Models (Quantitative Applications in the Social Sciences). Sage Publications, Inc, annotated edition, sep 2008. ISBN 1412949645. URL http://www.worldcat.org/isbn/1412949645.

Kenneth Gillingham, Richard G. Newell, and William A. Pizer. Modeling endogenous technological change for climate policy analysis. Energy Economics, 30(6):2734-2753, 2008. ISSN 01409883. doi: 10.1016/j.eneco.2008.03.001.

Wynne Godley and Marc Lavoie. A simple model of three economies with two currencies: The eurozone and the USA. Cambridge Journal of Economics, 31(1):1-23, 2007. ISSN 0309166X. doi: 10.1093/cje/bel010.

Joseph Golec and John A. Vernon. Financial Effects of Pharmaceutical Price Regulation on R\&D Spending by EU versus US Firms. PharmacoEconomics, 28(8):615-628, aug 2010. ISSN 1170-7690. doi: 10.2165/11535580-000000000-00000. URL http://www.ssrn.com/abstract=932989http://link. springer. com/10.2165/11535580-000000000-00000.

André Grimaud and Luc Rouge. Environment, Directed Technical Change and Economic Policy. Environmental and Resource Economics, 41(4):439-463, 2008. ISSN 0924-6460. doi: 10.1007/s10640-008-9201-4. URL http://link.springer.com/10. 1007/s10640-008-9201-4.

Dominique Guellec and Bruno van Pottelsberghe de la Potterie. R\&D and Productivity Growth. OECD Economic Studies, 2001(2):103-126, jan 2003. ISSN 0255-0822. doi: 10.1787/eco_studies-v2001-art12-en. URL http://www.oecd-ilibrary. org/economics/r-d-and-productivity-growth\{_\}eco\{_\}studies-v2001-art12-en.

A. Haas and C. Jaeger. Agents, Bayes, and Climatic Risks - a modular modelling approach. Advances in Geosciences, 4:3-7, aug 2005. ISSN 1680-7359. doi: 10.5194/adgeo-4-3-2005. URL http://www.adv-geosci.net/4/3/2005/.

Lukas Hardt and Daniel W. O'Neill. Ecological Macroeconomic Models: Assessing Current Developments. Ecological Economics, 134:198-211, apr 2017. ISSN 09218009. doi: 10.1016/j.ecolecon.2016.12.027. URL http://www.sciencedirect.com/ science/article/pii/S0921800916303202.

Horace Herring and Robin Roy. Technological innovation, energy efficient design and the rebound effect. Technovation, 27(4):194-203, 2007. ISSN 01664972. doi: http://dx.doi.org/10.1016/j.technovation.2006.11.004. URL http: //www.sciencedirect.com/science/article/pii/s016649720600112X.

John Hicks. The Theory of Wages. Macmillan, London, 1932.

Chris Hope. Critical issues for the calculation of the social cost of $\mathrm{CO} 2$ : why the estimates from PAGE09 are higher than those from PAGE2002. Climatic Change, 117(3):531-543, apr 2013. ISSN 0165-0009. doi: 10.1007/s10584-012-0633-z. URL http://link.springer.com/10.1007/s10584-012-0633-z.

IPCC. Fifth Assessment Report. Intergovernmental Panel on Climate Change (IPCC), Geneva, 2012.

IPCC. Sixth Assessment Report. IPCC, 2016.

Tim Jackson. Prosperity without Growth: Economics for Finite Planet. Routledge, 2009.

Tim Jackson, Peter A Victor, and Asjad Naqvi. Towards a Stock-Flow Consistent Ecological Macroeconomics. PASSAGE Working Paper 15/02. Guildford: University of Surrey, 2015.

Adam B. Jaffe, Richard G. Newell, and Robert N. Stavins. Technological Change and the Environment. Handbook of Environmental Economics, 1(November):461-516, 2003. ISSN 15740099. doi: 10.1016/S1574-0099(03)01016-7. URL http://www.sciencedirect.com/science/article/pii/S1574009903010167.

Sondes Kahouli-Brahmi. Technological learning in energy-environment-economy modelling: A survey. Energy Policy, 36(1): 138-162, 2008. ISSN 03014215. doi: 10.1016/j.enpol.2007.09.001.

Nicholas Kaldor. A Model of Economic Growth. The Economic Journal, 67(268):591, dec 1957. ISSN 00130133. doi: 10.2307/2227704. URL http://www.jstor.org/stable/10.2307/2227704.

Michal Kalecki. Selected Essays on the Dynamics of the Capitalist Economy 1933-1970. Cambridge University Press, 1971. 
Giorgos Kallis, Christian Kerschner, and Joan Martinez-Alier. The economics of degrowth. Ecological Economics, 84:172-180, dec 2012. ISSN 09218009. doi: 10.1016/j.ecolecon.2012.08.017. URL http://dx.doi.org/10.1016/j .ecolecon.2012.08.017.

Pasi Karjalainen. R\&D investments: The effects of different financial environments on firm profitability. Journal of Multinational Financial Management, 18(2):79-93, 2008. ISSN 1042444X. doi: 10.1016/j.mulfin.2007.02.006.

Charles Kennedy. Induced Bias in Innovation and the Theory of Distribution. The Economic Journal, 74(295):541, sep 1964. ISSN 00130133. doi: 10.2307/2228295. URL http://www.jstor.org/stable/10.2307/2228295?origin=crossref.

Kent A Klitgaard and Lisi Krall. Ecological economics, degrowth, and institutional change. Ecological Economics, 84:247-253, dec 2012. ISSN 09218009. doi: 10.1016/j.ecolecon.2011.11.008. URL http://linkinghub.elsevier.com/retrieve/pii/ S0921800911004897.

Simon Koesler and Michael Schymura. Substitution Elasticities in a CES Production Framework - Empirical Estimates using Non-Linear Least Squares Estimations. Economic Systems Research, 27(1):101-121, jan 2015. doi: 10.1080/09535314.2014. 926266. URL http://www.tandfonline.com/doi/abs/10.1080/09535314.2014.926266.

Tobias Kronenberg. Finding common ground between ecological economics and post-Keynesian economics. Ecological Economics, 69(7):1488-1494, may 2010. ISSN 09218009. doi: 10.1016/j.ecolecon.2010.03.002. URL http://linkinghub. elsevier.com/retrieve/pii/S0921800910000972.

Reiner Kümmel, Dietmar Lindenberger, and Florian Weiser. The economic power of energy and the need to integrate it with energy policy. Energy Policy, 86:833-843, 2015. ISSN 03014215. doi: 10.1016/j.enpol.2015.07.026. URL http: //dx.doi.org/10.1016/j.enpol.2015.07.026.

Francesco Lamperti, Mauro Napoletano, and Andrea Roventini. Preventing Environmental Disasters: Market-Based vs. Command-and-Control Policies. 2016.

Francesco Lamperti, Giovanni Dosi, Mauro Napoletano, Andrea Roventini, and Alessandro Sapio. Faraway, So Close: Coupled Climate and Economic Dynamics in an Agent-Based Integrated Assessment Model. 2017.

Francesco Lamperti, Antoine Mandel, Mauro Napoletano, Alessandro Sapio, Andrea Roventini, Tomas Balint, and Igor Khorenzhenko. Towards Agent-Based Integrated Assessment Models: Examples, Challenges, and Future Developments. Regional Environmental Change, (Online view), mar 2018. ISSN 1436-3798. doi: 10.1007/s10113-018-1287-9. URL http://link. springer.com/10.1007/s10113-018-1287-9.

Marc Lavoie. Post-Keynesian Economics: New Foundations. Book, 2:688, 2014. ISSN 0717-6163. doi: 10.1007/ s13398-014-0173-7.2. URL https://books.google. com/books?hl=en $\{\&\}$ lr=\{\&\}id=bv72AwAAQBAJ $\{\&\}$ pgis $=1$.

Marc Lavoie and Wynne Godley. Monetary economics: An integrated approach to credit, money, income, production and wealth. Palgrave Macmillan US, New York, 2nd edition, 2012. ISBN 0230500552. doi: 10.1111/j.1468-0335.2008.00655.x. URL http://doi.wiley.com/10.1111/j.1468-0335.2008.00655.x.

Andreas Löschel. Technological change in economic models of environmental policy: A survey. Ecological Economics, 43 (2-3):105-126, 2002. ISSN 09218009. doi: 10.1016/S0921-8009(02)00209-4. URL http://www. sciencedirect. com/science/ article/pii/S0921800902002094.

Christian Lutz, Bernd Meyer, Carsten Nathani, and Joachim Schleich. Endogenous technological change and emissions: The case of the German steel industry. Energy Policy, 33(9):1143-1154, 2005. ISSN 03014215. doi: 10.1016/j.enpol.2003.11.012.

Giacomo Marangoni and Massimo Tavoni. The Clean Energy R\&D Strategy For 2 Degree C. Climate Change Economics, 05 (01), feb 2014. ISSN 2010-0078. doi: 10.1142/S201000781440003X.

Mariana Mazzucato. The Green Entrepreneurial State. In Ian Scoones, Melissa Leach, and Peter Newell, editors, The Politics of Green Transformations, chapter 9, pages 134-152. Taylor \& Francis, New York, NY, USA, 2015.

Mariana Mazzucato. From market fixing to market-creating: a new framework for innovation policy. Industry and Innovation, 23(2):140-156, feb 2016. ISSN 1366-2716. doi: 10.1080/13662716.2016.1146124. URL http://www.tandfonline.com/doi/ full/10.1080/13662716.2016.1146124. 
Dennis Meadows, Donella Meadows, Jørgen Jorgen Randers, William W Behrens, and William Behrens III. The Limits to Growth. Universe Books, New York, 1972. ISBN 0876631650. doi: 10.1111/j.1752-1688.1972.tb05230.x.

Donella Meadows, Jorgen Randers, and Dennis Meadows. A Synopsis: Limits to Growth - 30 Year Update. Earthscan, 2004.

Antonio Minniti and Francesco Venturini. The long-run growth effects of R\&D policy. Research Policy, 46(1):316-326, feb 2017. ISSN 00487333. doi: 10.1016/j.respol.2016.11.006. URL http://linkinghub.elsevier.com/retrieve/pii/ S0048733316301950.

Irene Monasterolo and Marco Raberto. The EIRIN Flow-of-funds Behavioural Model of Green Fiscal Policies and Green Sovereign Bonds. Ecological Economics, 144(May 2016):228-243, feb 2018. ISSN 09218009. doi: 10.1016/j.ecolecon.2017. 07.029. URL http://dx.doi.org/10.1016/j.ecolecon.2017.07.029.

Asjad Naqvi. Modeling Growth, Distribution, and the Environment in a Stock-Flow Consistent Framework. WWWforEurope Policy Papers, 1(18):1-33, 2015.

Richard R. Nelson and Sidney G. Winter. In search of useful theory of innovation. Research Policy, 6(1):36-76, jan 1977. ISSN 00487333. doi: 10.1016/0048-7333(77)90029-4. URL http://linkinghub.elsevier.com/retrieve/pii/0048733377900294.

Richard R. Nelson and Sidney G. Winter. An Evolutionary Theory of Economic Change. Harvard University Press, Cambridge, MA, USA, 1982. URL https://www.jstor.org/stable/2232409?origin=crossref.

Richard G Newell, Adam B Jaffe, and Robert N Stavins. The Induced Innovation Hypothesis and Energy-Saving Technological Change. The Quarterly Journal of Economics, 114(3):941-975, aug 1999. ISSN 0033-5533. doi: 10.1162/003355399556188.

Michalis Nikiforos and Gennaro Zezza. Stock-Flow Consistent Macroeconomic Models: A Survey. Journal of Economic Surveys, 31(5):1204-1239, 2017. ISSN 14676419. doi: 10.1111/joes.12221.

Maria Nikolaidi and Engelbert Stockhammer. Minsky Models: A Structured Survey. Journal of Economic Surveys, 31(5): 1304-1331, 2017. doi: 10.1111/joes.12222. URL http://doi.wiley.com/10.1111/joes. 12222.

William Nordhaus. Managing the global commons: The economics of climate change. MIT Press, Cambridge, MA, USA, 1994.

William Nordhaus and Paul Sztorc. DICE 2013R : Introduction and User 's Manual with. Technical report, Yale University, 2013.

William D Nordhaus and Zili Yang. A Regional Dynamic General-Equilibrium Model of Alternative Climate-Change Strategies. American Economic Association, 86(4):741-765, 1996.

OECD. Towards Green Growth. Technical report, The Organisation for Economic Co-operation and Development (OECD), Paris, 2011. URL http://www.oecd.org/greengrowth/48224539.pdf.

OECD. Towards green growth? Tracking Progress. Technical report, The Organisation for Economic Co-operation and Development (OECD), Paris, France, 2015.

Vincent M. Otto, Andreas Löschel, and John Reilly. Directed technical change and differentiation of climate policy. Energy Economics, 30(6):2855-2878, nov 2008. ISSN 01409883. doi: 10.1016/j.eneco.2008.03.005. URL http://linkinghub. elsevier.com/retrieve/pii/S0140988308000480.

Robert S. Pindyck. The Use and Misuse of Models for Climate Policy. Review of Environmental Economics and Policy, 11(1): 100-114, 2017. ISSN 1750-6816. doi: 10.1093/reep/rew012. URL https://academic.oup.com/reep/article/3066301/The.

William A. Pizer and David Popp. Endogenizing technological change: Matching empirical evidence to modeling needs. Energy Economics, 30(6):2754-2770, 2008. ISSN 01409883. doi: 10.1016/j.eneco.2008.02.006.

Hector Pollitt, Anthony Barker, Jennifer Barton, Elke Pirgmaier, Christine Polzin, Stephan Lutter, Friedrich Hinterberger, and Andrea Stocker. A scoping study on the macroeconomic view of sustainability. Technical report, DG Environment, European Commission, 2010.

David Popp. Induced Innovation and Energy Prices. American Economic Review, 92(1):160-180, feb 2002. ISSN 0002-8282. doi: 10.1257/000282802760015658. URL http://pubs.aeaweb.org/doi/10.1257/000282802760015658.

David Popp. ENTICE: endogenous technological change in the DICE model of global warming. Journal of Environmental 
Economics and Management, 48(1):742-768, jul 2004. ISSN 00950696. doi: 10.1016/j.jeem.2003.09.002. URL http: //linkinghub.elsevier.com/retrieve/pii/S0095069603001220.

David Popp. Innovation in climate policy models: Implementing lessons from the economics of R\&D. Energy Economics, 28 (5-6):596-609, 2006. ISSN 01409883. doi: 10.1016/j.eneco.2006.05.007.

David Popp, Richard G. Newell, and Adam B. Jaffe. Energy, the Environment, and Technological Change. In Handbook of the Economics of Innovation, chapter 21, pages 873-937. Elsevier B.V., 2010. ISBN 2210-8807. doi: 10.1016/S0169-7218(10) 02005-8. URL http://linkinghub.elsevier.com/retrieve/pii/S0169721810020058.

David C. Popp. The effect of new technology on energy consumption. Resource and Energy Economics, 23(3):215-239, jul 2001. ISSN 09287655. doi: 10.1016/S0928-7655(00)00045-2. URL http://linkinghub.elsevier.com/retrieve/pii/ S0928765500000452.

Devesh Raval. Estimation of a CES Production Function With Factor Augmenting Technology. 2011.

Kate Raworth. Doughnut Economics: Seven Ways to Think Like a 21st Century Economist. Chelsea Green Publishing, VT, 2017.

Bernhard Rengs, Manuel Scholz-Wäckerle, Ardjan Gazheli, Miklós Antal, and Jeroen van den Bergh. Testing innovation, employment and distributional impacts of climate policy packages in a macro-evolutionary systems setting. 2015 . URL https://ideas.repec.org/p/feu/wfewop/y2015m2d0i83.html.

Till Requate. Timing and Commitment of Environmental Policy, Adoption of New Technology, and Repercussions on R\&D. Environmental 8 Resource Economics, 31(2):175-199, jun 2005. ISSN 0924-6460. doi: 10.1007/s10640-005-1770-x. URL http://link.springer.com/10.1007/s10640-005-1770-x.

Armon Rezai and Sigrid Stagl. Ecological macroeconomics: Introduction and review. Ecological Economics, 121(9):181-185, jan 2016. ISSN 09218009. doi: 10.1016/j.ecolecon.2015.12.003. URL http://linkinghub.elsevier.com/retrieve/pii/ S0921800915004747.

Armon Rezai, Lance Taylor, and Reinhard Mechler. Ecological macroeconomics: An application to climate change. Ecological Economics, 85:9-76, 2013. ISSN 09218009. doi: 10.1016/j.ecolecon.2012.10.008. URL http://dx.doi.org/10.1016/j. ecolecon.2012.10.008.

Armon Rezai, Lance Taylor, and Duncan Foley. Economic Growth, Income Distribution, and Climate Change. Ecological Economics, 146(October 2017):164-172, 2018. ISSN 09218009. doi: 10.1016/j.ecolecon.2017.10.020. URL http: //linkinghub.elsevier.com/retrieve/pii/S0921800917312041.

J. Robinson. The Accumulation of Capital. Macmillan, London, 1956.

Johan Rockström, Will Steffen, Kevin Noone, Åsa Persson, F. Stuart III Chapin, Eric Lambin, Timothy M. Lenton, Marten Scheffer, Carl Folke, Hans Joachim Schellnhuber, Björn Nykvist, Cynthia A. de Wit, Terry Hughes, Sander van der Leeuw, Henning Rodhe, Sverker Sörlin, Peter K. Snyder, Robert Costanza, Uno Svedin, Malin Falkenmark, Louise Karlberg, Robert W. Corell, Victoria J. Fabry, James Hansen, Brian Walker, Diana Liverman, Katherine Richardson, Paul Crutzen, and Jonathan Foley. Planetary Boundaries: Exploring the Safe Operating Space for Humanity. Ecology and Society, 14(2), 2009. ISSN 1708-3087. doi: 10.5751/ES-03180-140232. URL http://www.ecologyandsociety.org/vol14/iss2/art32/.

Paul M. Romer. Endogenous Technological Change. Journal of Political Economy, 98(5, Part 2):S71-S102, oct 1990. ISSN 0022-3808. doi: 10.1086/261725. URL http://www.journals.uchicago.edu/doi/10.1086/261725.

Inge Røpke. Complementary system perspectives in ecological macroeconomics - The example of transition investments during the crisis. Ecological Economics, 121:237-245, 2016. ISSN 09218009. doi: 10.1016/j.ecolecon.2015.03.018. URL http: //dx.doi.org/10.1016/j.ecolecon.2015.03.018.

Peter L. Rousseau. Biased and Unbiased Technological Change. In The New Palgrave Dictionary of Economics, pages 1-4. Palgrave Macmillan UK, London, 2008. doi: 10.1057/978-1-349-95121-5_89-2. URL http://link.springer.com/10.1057/ 978-1-349-95121-5\{_\}89-2. 
Karolina Safarzyńska and Jeroen C.J.M. van den Bergh. Integrated crisis-energy policy: Macro-evolutionary modelling of technology, finance and energy interactions. Technological Forecasting and Social Change, 114:119-137, jan 2017. ISSN 00401625. doi: 10.1016/j.techfore.2016.07.033. URL http://www.sciencedirect.com/science/article/pii/S0040162516301901.

Joseph Schumpeter. The Theory of Economic Development, volume 1. Transaction Publishers, New Brunswick, New Jersey, 1983 editi edition, 1934. ISBN 9788578110796. doi: 10.1017/CBO9781107415324.004.

S. Scrieciu, A. Rezai, and R. Mechler. On the economic foundations of green growth discourses: the case of climate change mitigation and macroeconomic dynamics in economic modeling. Wiley Interdisciplinary Reviews: Energy and Environment, 2(3):251-268, may 2013. ISSN 20418396. doi: 10.1002/wene.57. URL http://doi.wiley.com/10.1002/wene.57.

Mark Setterfield. Post-Keynesian macrodynamics and path-dependent growth. European Journal of Economics and Economic Policies: Intervention, 8(2):299-316, 2011. ISSN 20527764. doi: 10.4337/ejeep.2011.02.06. URL http://www.elgaronline. com/abstract/journals/ejeep/8-2/ejeep.2011.02.06.xml.

Peter Skott. Wage inequality and overeducation in a model with efficiency wages. Canadian Journal of Economics, 39(1):94123, feb 2006. ISSN 0008-4085. doi: 10.1111/j.0008-4085.2006.00340.x. URL http://doi.wiley.com/10.1111/j.0008-4085. $2006.00340 . x$.

Sjak Smulders. Environmental policy and sustainable economic growth. De Economist, 143(2):163-195, may 1995. ISSN 0013-063X. doi: 10.1007/BF01384534. URL http://link.springer.com/10.1007/BF01384534.

Robert M Solow. A Contribution to the Theory of Economic Growth. The Quarterly Journal of Economics, 70(1):65, feb 1956. ISSN 00335533. doi: 10.2307/1884513. URL http://www.jstor.org/stable/1884513.

Clive L. Spash. New foundations for ecological economics. Ecological Economics, 77(C):36-47, 2012. ISSN 09218009. doi: 10.1016/j.ecolecon.2012.02.004. URL http://linkinghub.elsevier.com/retrieve/pii/S092180091200050X.

Will Steffen, Katherine Richardson, Johan Rockström, Sarah Cornell, Ingo Fetzer, Elena Bennett, R Biggs, Stephen R Carpenter, Cynthia a. de Wit, Carl Folke, Georgina Mace, Linn M Persson, R Veerabhadran, Belinda Reyers, and Sverker Sörlin. Planetary Boundaries: Guiding human development on a changing planet. Science Xpress, January, 2015.

Nicholas Stern. Economics: Current climate models are grossly misleading. Nature, 530(7591):407-409, feb 2016. ISSN 0028-0836. doi: 10.1038/530407a. URL http://www.nature.com/doifinder/10.1038/530407a.

Engelbert Stockhammer. Is the NAIRU Theory a Monetarist, New Keynesian, Post Keynesian or a Marxist theory? Metroeconomica, 59(3):479-510, 2008. ISSN 1467999X. doi: 10.1111/j.1467-999X.2008.00314.x.

Engelbert Stockhammer. Wage norms, capital accumulation, and unemployment: A post-Keynesian view. Oxford Review of Economic Policy, 27(2):295-311, 2011. ISSN 14602121. doi: 10.1093/oxrep/grr013.

Ian Sue Wing. Representing induced technological change in models for climate policy analysis. Energy Economics, 28(5-6): 539-562, 2006a. ISSN 01409883. doi: 10.1016/j.eneco.2006.05.009.

Ian Sue Wing. Induced technological change: Firm innovatory responses to environmental regulation. 2006b. URL http: //www.som.yale.edu/faculty/nok4/files/seminar/sue\{_\}wing.pdf.

Leo Sveikauskas. R\&D and Productivity Growth: A Review of the Literature. 2007.

Daniele Tavani. Wage bargaining and induced technical change in a linear economy: Model and application to the US (19632003). Structural Change and Economic Dynamics, 23(2):117-126, 2012. ISSN 0954349X. doi: 10.1016/j.strueco.2011.11.001.

Daniele Tavani and Luca Zamparelli. Endogenous Technical Change in Alternative Theories of Growth and Distribution. Journal of Economic Surveys, 31(5):1272-1303, dec 2017. ISSN 09500804. doi: 10.1111/joes.12220. URL http://doi. wiley.com/10.1111/joes. 12220 .

Leigh Tesfatsion. Agent-Based Computational Economics: A Constructive Approach to Economic Theory. In Leigh Tesfatsion and Kenneth L Judd, editors, Handbook of Computational Economics, volume 2 of General Handbooks in Economics, pages 831-880. Elsevier/North-Holland, Amsterdam, 2006.

Stefan Thurner and Sebastian Poledna. DebtRank-transparency: Controlling systemic risk in financial networks. Scientific 
Reports, 3, 2013. ISSN 20452322. doi: 10.1038/srep01888.

James Tobin. Money and Finance in the Macroeconomic Process. Journal of Money, Credit and Banking, 14(2):171-204, 1982. Richard S.J. Tol. On the optimal control of carbon dioxide emissions: an application of FUND. Environmental Modeling and Assessment, 2(3):151-163, 1997. ISSN 14202026. doi: 10.1023/A:1019017529030. URL http://link.springer.com/10. 1023/A : 1019017529030.

Jeroen C J M Van den Bergh. Environment versus growth - A criticism of "degrowth" and a plea for "a-growth". Ecological Economics, 70(5):881-890, 2011. ISSN 09218009. doi: 10.1016/j.ecolecon.2010.09.035. URL http://dx.doi.org/10.1016/ j.ecolecon.2010.09.035.

Jeroen C J M van den Bergh. Environmental and climate innovation: Limitations, policies and prices. Technological Forecasting and Social Change, 80(1):11-23, 2013. ISSN 00401625. doi: 10.1016/j.techfore.2012.08.004. URL http://dx.doi.org/10. 1016/j.techfore.2012.08.004.

Jeroen C. J. M. van den Bergh. A third option for climate policy within potential limits to growth. Nature Climate Change, 7(2):107-112, 2017. ISSN 1758-678X. doi: 10.1038/nclimate3113. URL http://www.nature.com/doifinder/10.1038/ nclimate3113.

B.C.C van der Zwaan, R Gerlagh, G, Klaassen, and L Schrattenholzer. Endogenous technological change in climate change modelling. Energy Economics, 24(1):1-19, jan 2002. ISSN 01409883. doi: 10.1016/S0140-9883(01)00073-1.

Till van Treeck. A synthetic, stock-flow consistent macroeconomic model of 'financialisation'. Cambridge Journal of Economics, 33(3):467-493, may 2009. ISSN 0309-166X. doi: 10.1093/cje/ben039. URL http://cje.oxfordjournals.org/cgi/doi/10. 1093/cje/ben039.

P. J. Verdoorn. Verdoorn's Law in Retrospect: A Comment. The Economic Journal, 90(358):382, jun 1980. ISSN 00130133. doi: 10.2307/2231798. URL http://www.jstor.org/stable/2231798?origin=crossref.

Peter Victor. Managing without Growth: Slower by Design, Not Disaster. Edward Elgar Publishing Ltd., Cheltenham, UK, 2008.

Peter A Victor. Growth, degrowth and climate change: A scenario analysis. Ecological Economics, 84(C):206-212, 2012. URL http://ideas.repec.org/a/eee/ecolec/v84y2012icp206-212.html.

Peter A. Victor and Gideon Rosenbluth. Managing without growth. Ecological Economics, 61(2-3):492-504, 2007. ISSN 09218009. doi: 10.1016/j.ecolecon.2006.03.022.

Francesco Vona and Fabrizio Patriarca. Income inequality and the development of environmental technologies. Ecological Economics, 70(11):2201-2213, 2011. ISSN 09218009. doi: 10.1016/j.ecolecon.2011.06.027.

Vlasios Voudouris, Robert Ayres, Andre Cabrera Serrenho, and Daniil Kiose. The economic growth enigma revisited: The EU-15 since the 1970s. Energy Policy, 86:812-832, 2015. ISSN 03014215. doi: 10.1016/j.enpol.2015.04.027.

Martin L Weitzman. GHG Targets as Insurance Against Catastrophic Climate Damages. Journal of Public Economic Theory, 14(2):221-244, mar 2012. ISSN 10973923. doi: 10.1111/j.1467-9779.2011.01539.x. URL http://doi.wiley.com/10.1111/j. $1467-9779.2011 .01539 . x$.

Paul Windrum, Tommaso Ciarli, and Chris Birchenhall. Consumer Heterogeneity and the Development of Environmentally Friendly Technologies. Technological Forecasting and Social Change, 76(4):533-551, 2009. ISSN 00401625. doi: 10.1016/j. techfore.2008.04.011.

Luca Zamparelli. Induced Innovation, Endogenous Technical Change and Income Distribution in a Labor-Constrained Model of Classical Growth. Metroeconomica, 66(2):243-262, may 2015. ISSN 00261386. doi: 10.1111/meca.12068. URL http: //doi.wiley.com/10.1111/meca.12068.

G Zezza. Dynamic properties of stock-flow models with stable stock-flow norms. 2003. 


\section{Appendix A. Parameters}

Table A.1: Calibration parameters

\begin{tabular}{|c|c|c|c|}
\hline Parameter & Description & Value & Equation \\
\hline$\tau^{R}$ & Resource tax & 0.1 & 10 \\
\hline$\delta$ & Depreciation rate & 0.1 & 15,16 \\
\hline$r_{l}$ & Interest on loans & 0.002 & 19,32 \\
\hline$\beta$ & Loan repayment rate & 0.05 & 19,22 \\
\hline$\theta$ & Markup costs & 0.1 & 20 \\
\hline$\tau^{F}$ & Profit tax on Firms & 0.2 & 23 \\
\hline$\mu$ & Share of profits in private $R \& D$ & 0.2 & 24 \\
\hline$r_{d}$ & Interest on deposits & 0.001 & $26,27,32$ \\
\hline$\tau^{H}$ & Income tax on Households & 0.2 & 28 \\
\hline$\alpha_{1}$ & MPC Income & 0.75 & 30 \\
\hline$\alpha_{2}$ & MPC Wealth & 0.05 & 30 \\
\hline$\tau^{B}$ & Profit tax on Banks & 0.2 & 33 \\
\hline$\psi$ & Government R\&D as a share of expenditure & 0.015 & 37 \\
\hline$\epsilon^{G}$ & Output-to-emissions ratio & 0.0001 & 38 \\
\hline$\lambda_{1 G}$ & Public R\&D investment in Labor & 0.33 & 39 \\
\hline$\lambda_{3 G}$ & Public R\&D investment in Resource & 0.33 & 39 \\
\hline$\lambda_{10}$ & Autonomous R\&D investment in Labor & 0.7 & 39 \\
\hline$\lambda_{30}$ & Autonomous R\&D investment in Resource & 0.15 & 39 \\
\hline$\lambda_{11}$ & Sensitivity of Labor investment to Labor costs & 0.05 & 39 \\
\hline$\lambda_{12}$ & Sensitivity of Labor investment to Capital costs & -0.025 & 39 \\
\hline$\lambda_{13}$ & Sensitivity of Labor investment to Resource costs & -0.025 & 39 \\
\hline$\lambda_{31}$ & Sensitivity of Resource investment to Labor costs & -0.025 & 39 \\
\hline$\lambda_{32}$ & Sensitivity of Resource investment to Capital costs & 0.05 & 39 \\
\hline$\lambda_{33}$ & Sensitivity of Resource investment to Resource costs & -0.025 & 39 \\
\hline
\end{tabular}


Table A.2: Adjustment parameters

\begin{tabular}{clcc}
\hline Parameter & Description & Value & Equation \\
\hline$\gamma_{\omega}$ & Past wage growth & 0.01 & 6 \\
$\gamma_{W}$ & Wage share target & 0.001 & 6 \\
$\gamma_{\Omega}$ & Wage share adjustment & 0.001 & 7 \\
$\gamma_{i}$ & Rate of investment & 0.4 & 16 \\
$\gamma_{p}$ & Price adjustment & 0.08 & 21 \\
$\gamma_{g}$ & Government spending adjustment & 0.05 & 35 \\
$\gamma_{m}$ & Productivity growth & 0.4 & 41 \\
\hline
\end{tabular}




\section{Appendix B. CES input demand}

\section{Appendix B.1. Model extension}

The production function specified in Eq. 2 is extended here to the general Constant Elasticity of Substitution (CES) form with $m$ inputs (Acemoglu 2002; Raval 2011; Koesler and Schymura 2015):

$$
y_{t}=\left(\sum_{m} \alpha_{m}\left(\epsilon_{t}^{m} m_{t}\right)^{\rho}\right)^{1 / \rho}
$$

where $y_{t}$ is the total real output defined at time $t$ (Eq. 2). $\alpha_{m}$ is the relative share of input $m$ in the output such that $\sum_{m} \alpha_{m}=1$. Usually $\alpha_{m}$ are set equal implying that all the inputs have equal weights in the production function but are usually subject to empirical estimation (Koesler and Schymura 2015). $\epsilon_{t}^{m}$ is the input $m$-augmenting productivity that evolves with time (see Eq. 42). $\rho=(\sigma-1) / \sigma$ where $\sigma$ is the elasticity of substitution. If $\sigma \rightarrow \infty(\rho \rightarrow 1)$, then the inputs are perfect substitutes, if $\sigma \rightarrow 0(\rho \rightarrow-\infty)$, then the inputs are perfect complements, and if $\sigma \rightarrow 1(\rho \rightarrow 0)$, the production function takes the usual Cobb-Douglas form. In general we are interested in the case of complementarity $(\sigma<1)$ or substitutability $(\sigma>1)$ of inputs.

The generic cost function of the can be defined as

$$
C_{t}=\left(\sum_{m} p_{t}^{m} m_{t}\right)
$$

In standard models one calculates the input requirements for producing a given level of output $Y_{t}$ given input prices $p_{t}^{m}$ by minimizing the cost function $C_{t}$ subject to the output function $y_{t}$. The generic demand function of input $m_{t}$ can be derived as follows:

$$
m_{t}=\frac{y_{t}}{\epsilon_{t}^{m}} \frac{\left(\frac{p_{t}^{m}}{\alpha_{m}}\right)^{\frac{1}{\rho-1}}}{\left(\sum_{m} \alpha_{m}\left(\frac{p_{t}^{m}}{\alpha_{m}}\right)^{\frac{\rho}{\rho-1}}\right)^{\frac{1}{\rho}}}
$$

\section{Appendix B.2. Simulations}

In order to operationalize the CES input demand function derived in Equation B.3, for three inputs $m=$ $\{L, K, R\}$, we assume that the shares are set equal such that $\alpha_{L}=0.33, \alpha_{K}=0.33, \alpha_{R}=1-\alpha_{L}-\alpha_{K}=0.333$. The modified Labor (Eq. 4), Capital (Eq. 14), and Resource (Eq. 9) input demand functions are derived as: 


$$
\begin{aligned}
& L_{t}=\frac{y_{t}}{\epsilon_{t}^{L}} \frac{\left(\frac{p_{t}^{L}}{\alpha_{L}}\right)^{\frac{1}{\rho-1}}}{\left(\alpha_{L}\left(\frac{p_{t}^{L}}{\alpha_{L}}\right)^{\frac{\rho}{\rho-1}}+\alpha_{K}\left(\frac{p_{t}^{K}}{\alpha_{K}}\right)^{\frac{\rho}{\rho-1}}+\left(1-\alpha_{L}-\alpha_{K}\right)\left(\frac{p_{t}^{R}}{1-\alpha_{L}-\alpha_{K}}\right)^{\frac{\rho}{\rho-1}}\right)^{\frac{1}{\rho}}} \\
& k_{t}^{T}=\frac{y_{t}}{\epsilon_{t}^{K}} \frac{\left(\frac{p_{t}^{K}}{\alpha_{K}}\right)^{\frac{1}{\rho-1}}}{\left(\alpha_{L}\left(\frac{p_{t}^{L}}{\alpha_{L}}\right)^{\frac{\rho}{\rho-1}}+\alpha_{K}\left(\frac{p_{t}^{K}}{\alpha_{K}}\right)^{\frac{\rho}{\rho-1}}+\left(1-\alpha_{L}-\alpha_{K}\right)\left(\frac{p_{t}^{R}}{1-\alpha_{L}-\alpha_{K}}\right)^{\frac{\rho}{\rho-1}}\right)^{\frac{1}{\rho}}}\left(\frac{p_{t}^{R}}{1-\alpha_{L}-\alpha_{K}}\right)^{\frac{1}{\rho-1}} \\
& R_{t}=\frac{y_{t}}{\epsilon_{t}^{R}} \frac{\left.\alpha_{L}\left(\frac{p_{t}^{L}}{\alpha_{L}}\right)^{\frac{\rho}{\rho-1}}+\alpha_{K}\left(\frac{p_{t}^{K}}{\alpha_{K}}\right)^{\frac{\rho}{\rho-1}}+\left(1-\alpha_{L}-\alpha_{K}\right)\left(\frac{p_{t}^{R}}{1-\alpha_{L}-\alpha_{K}}\right)^{\frac{\rho}{\rho-1}}\right)^{\frac{1}{\rho}}}{\left(\alpha^{\prime}\right.}
\end{aligned}
$$

The remaining model structure is kept the same. The $B A U$ and the $R T a x+$ scenario are repeated from Experiment 1 (Sec. 4.1). We set $\sigma=0.001$ to replicate the complementary production function and $\sigma=2$ to make the inputs substitutable. A higher value of sigma implies perfect substitutability across the inputs, implying that corner solutions can exist where just one good can be used for producing all the output, a highly implausible scenario. The results are explored in Figure B.1 and B.2 below.

The two thick lines represent the business-as-usual from complementary inputs case ( $B A U$, thick solid line) and the substitutable inputs case $(B A U(s u b)$, thick dashed line). To make the results comparable, the initial values are kept the same, but at $Y$ ear $=1$, the elasticity parameter is switched from $\sigma=0.001$ to $\sigma=2$ which results in adjustments in the model. For the two BAU scenarios, the immediate impact is clear in Figure B.1. There is switch away from labor to more resource and capital intensive technologies due to cheaper input costs. This results in an overall general reduction in the price levels (Fig. B.1c), increasing GDP (Fig. B.1a). Share of investment in GDP rises (Fig. B.1e), while consumption (Fig. B.1d) and government shares (Fig. B.1f) fall below the BAU scenario once the model stabilizes. An increase in the output results is a rise in emissions (Fig. B.1g). There is a reduction in R\&D intensity (Fig. B.1h), while the share of public R\&D eventually stabilizes above the BAU scenario (Fig. B.1i).

In Figure B.2, the switch from complementary to substitute inputs results in an increase in the capital (Fig. B.2b) and resource share (Fig. B.2c) in costs, off-setting the share of labor (Fig. B.2a). Do to an increase in the wage rate (Fig. B.1b), share of labor (Fig. B.2a) in total costs continues to rise after the initial decline. Since the slope of the costs functions do not change after the initial adjustment (Fig. B.2a-c), share of R\&D investment across the two BAU scenarios stays the same (Fig. B.2d-f).

For the two RTax + and $R T a x+(s u b)$ experiments, shown as thin solid and dashed lines respectively, we evaluate the impacts of a continuously increasing tax increase across the two production functions. As the Resource costs go up in both scenarios (Fig. B.2c), R\&D investment is shifted away from Labor (Fig. B.2d) towards Resources (Fig. B.2f). In the Leontief case, the inputs evolve independently resulting in rising 
Figure B.1: Experiment 3 - Macro indicators

(a) Real GDP $(y)$

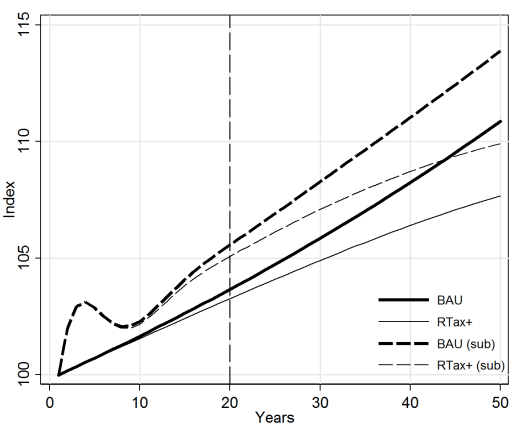

(d) Consumption share $(C / Y)$

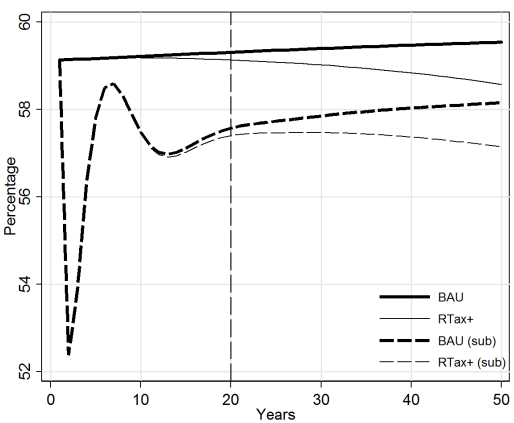

(g) Emissions (Emm)

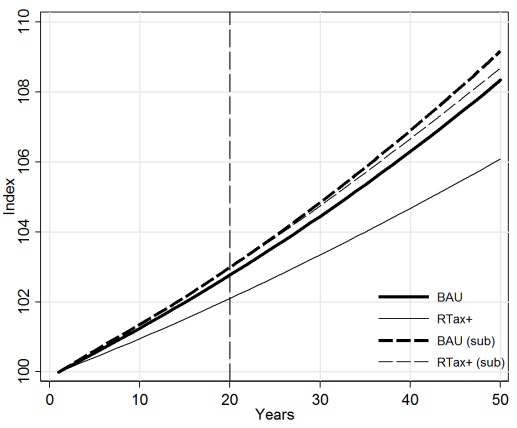

(b) Wage rate $\left(p_{t}^{L}\right)$

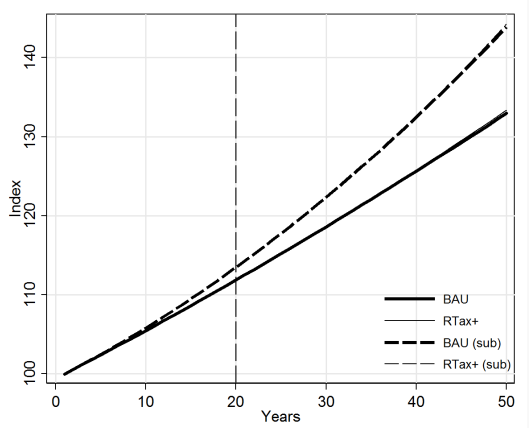

(e) Investment share $(I / Y)$

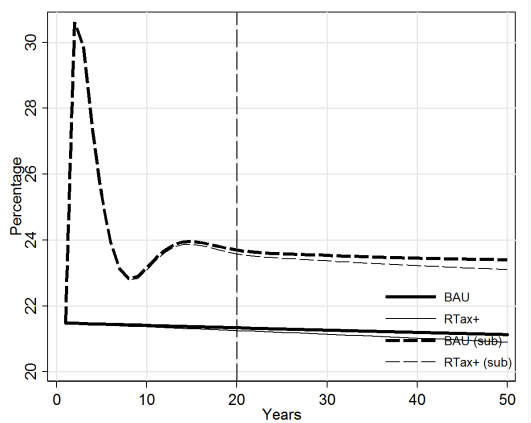

(h) R\&D Intensity $(R \& D / Y)$

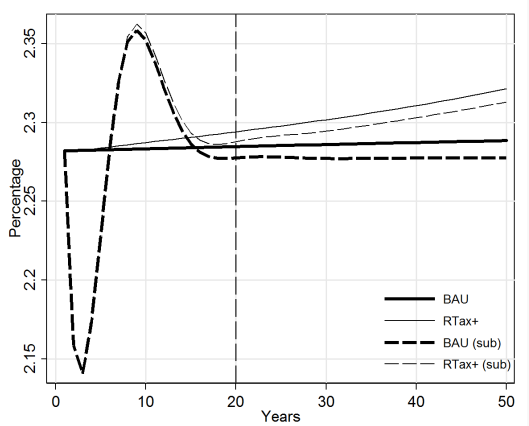

(c) Prices $(p)$

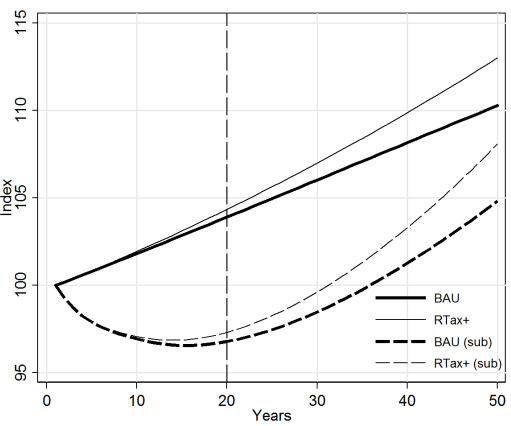

(f) Government share $(G / Y)$

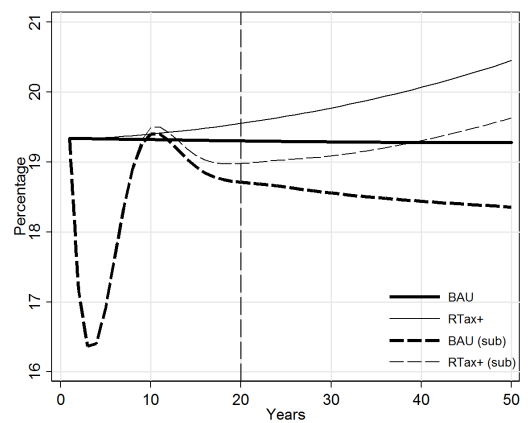

(i) Public R\&D share $\left(R \& D^{G} / R \& D\right)$

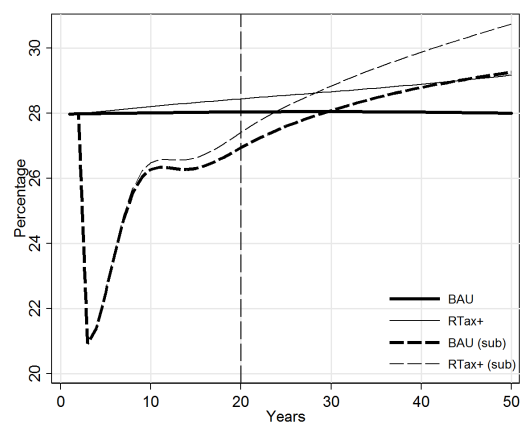


Figure B.2: Experiment $3-\mathrm{R} \& \mathrm{D}$ and productivity

(a) Labor share in costs

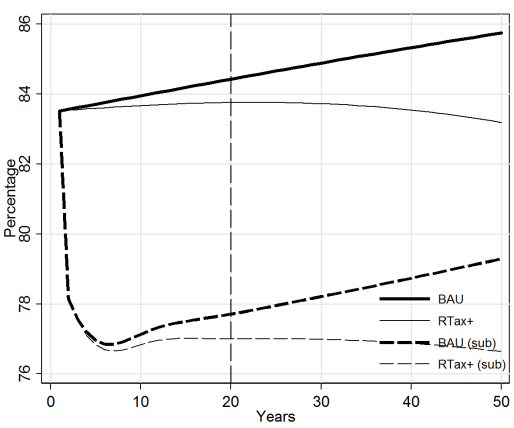

(d) Labor share in R\&D $\left(\phi^{L}\right)$

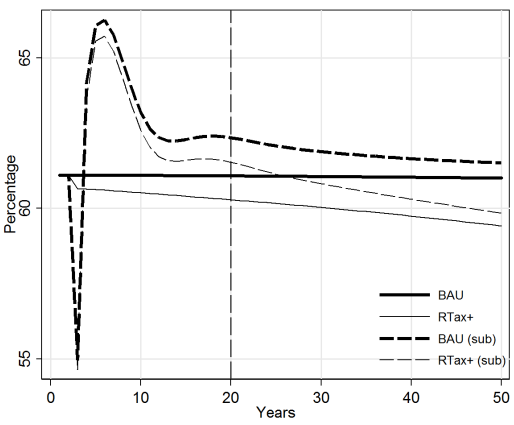

(g) Labor productivity $\left(\epsilon^{L}\right)$

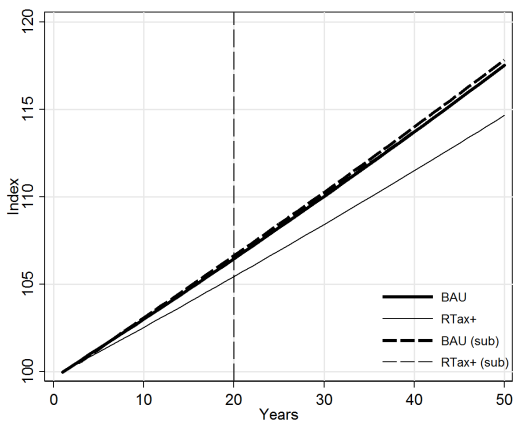

(b) Capital share in costs

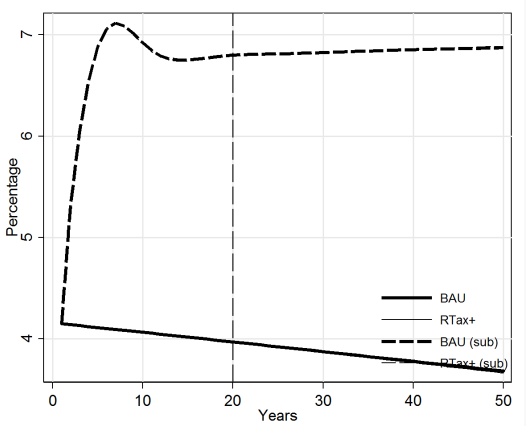

(e) Capital share in $\mathrm{R} \& \mathrm{D}\left(\phi^{K}\right)$

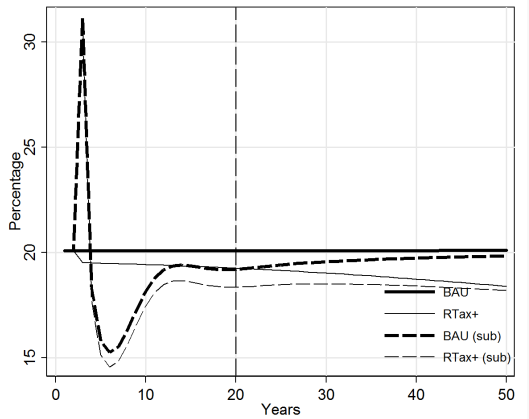

(h) Capital productivity $\left(\epsilon^{K}\right)$

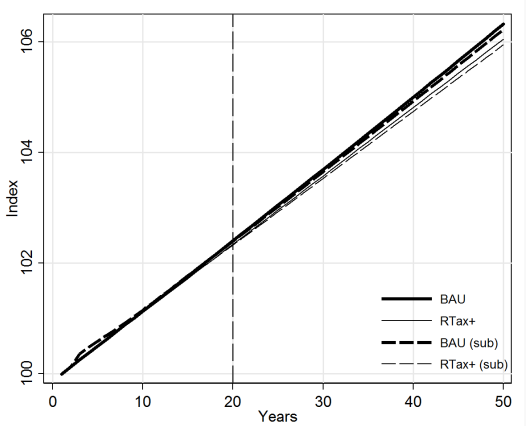

(c) Resource share in costs

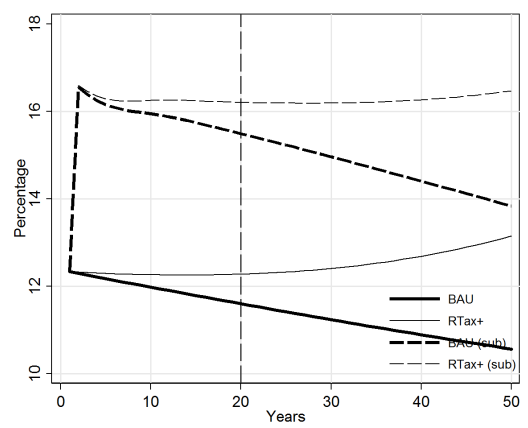

(f) Resource share in $\mathrm{R} \& \mathrm{D}\left(\phi^{R}\right)$

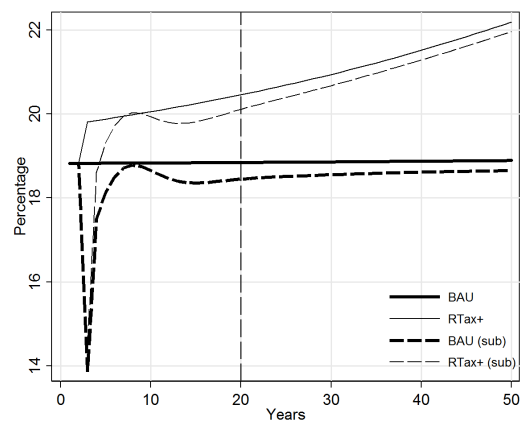

(i) Resource productivity $\left(\epsilon^{R}\right)$

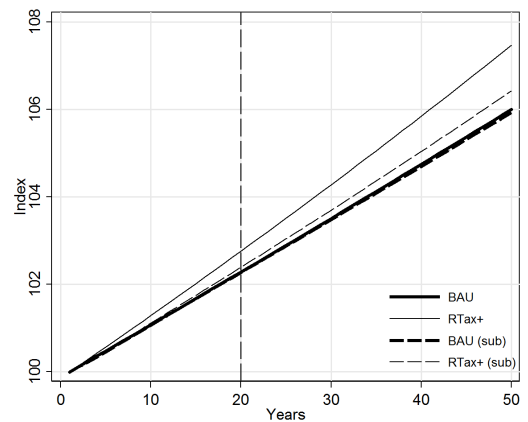


costs (Fig. B.1c) due to lower investment in Labor. In the substitution case, trade-offs between Resources and Labor allows firms to not only invest more in Resources but also substitute Labor (Fig. B.2a) with higher Resource use (Fig. B.2c). As a result, the weight of Labor in costs declines (Fig. B.2a), rsulting in lower R\&D spending towards it (Fig. B.2d), resulting in lower labor-specific productivity gains (Fig. B.2g). Similarly the productivity gains are also only slightly above the BAU for Resources (Fig. B.2i). As a result emissions fall but only slightly in the RTax $+(s u b)$ scenario while in $R T a x+$ they fall below the BAU level due to a highly induced technical change (Fig. B.1g).

This result is also summarized in Figure B.3 which shows that the relative efficiency of labor stays high and close to the BAU scenario in the case of substitutability. In the case of complementarities, the efficiency gains in Resources outweighs the gains in Labor.

Figure B.3: Experiment 3 - Technological development of inputs

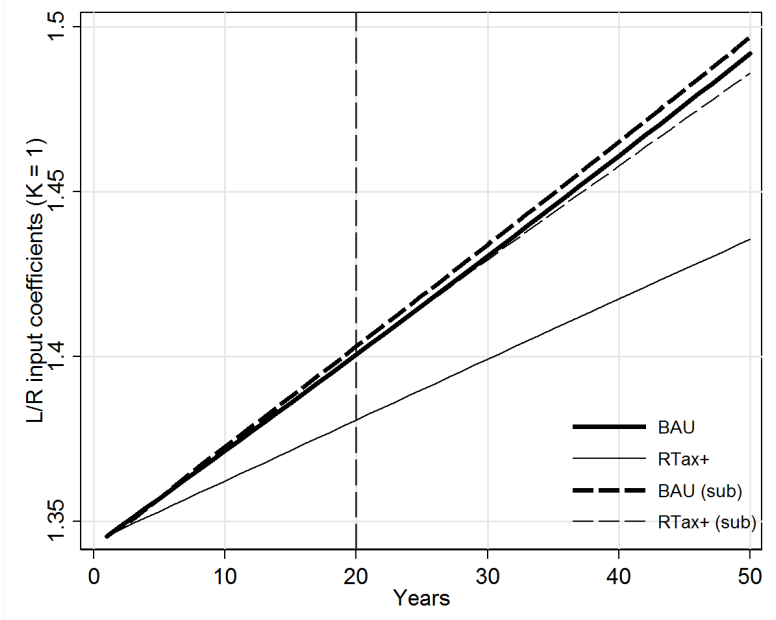

These results are not far from what has been discussed in mainstream literature. For example, Acemoglu (2002) highlights that when inputs are complements, a resource-saving technological change automatically translates into labor-saving technological change. If the inputs are substitutes, then an efficiency gain in one input, will change the demand towards that specific input. While in the former, constant intervention in needed in the Resource sector to prevent to Labor sector directing resources towards it, in the latter a simple tax on the dirty input and subsidy on the clean input is sufficient to induce a "green" transition.

While this is a first attempt at the use of the CES input demand function in an SFC model, and the results are preliminary, it provides one way of making non-mainstream models comparable with mainstream ones. However flexible CES functions forms needs to be further tested for parameter sensitivities since the feedbacks triggered by policies across the substitute and the complementary cases are non-trivial and can be potentially result in massively different policy conclusions. 